IZA DP No. 8169

Trust and In-Group Favoritism in a Culture of Crime

Stephan Meier

Lamar Pierce

Antonino Vaccaro

May 2014 


\title{
Trust and In-Group Favoritism in a Culture of Crime
}

\author{
Stephan Meier \\ Columbia University, Graduate School of Busines, \\ NBER and IZA \\ Lamar Pierce \\ Washington University in St. Louis, Olin Business School \\ Antonino Vaccaro \\ University of Navarra, IESE Business School
}

\author{
Discussion Paper No. 8169 \\ May 2014
}

\author{
IZA \\ P.O. Box 7240 \\ 53072 Bonn \\ Germany
}

Phone: $+49-228-3894-0$

Fax: +49-228-3894-180

E-mail: iza@iza.org

Any opinions expressed here are those of the author(s) and not those of IZA. Research published in this series may include views on policy, but the institute itself takes no institutional policy positions. The IZA research network is committed to the IZA Guiding Principles of Research Integrity.

The Institute for the Study of Labor (IZA) in Bonn is a local and virtual international research center and a place of communication between science, politics and business. IZA is an independent nonprofit organization supported by Deutsche Post Foundation. The center is associated with the University of Bonn and offers a stimulating research environment through its international network, workshops and conferences, data service, project support, research visits and doctoral program. IZA engages in (i) original and internationally competitive research in all fields of labor economics, (ii) development of policy concepts, and (iii) dissemination of research results and concepts to the interested public.

IZA Discussion Papers often represent preliminary work and are circulated to encourage discussion. Citation of such a paper should account for its provisional character. A revised version may be available directly from the author. 


\section{ABSTRACT}

\section{Trust and In-Group Favoritism in a Culture of Crime*}

We use experiments in high schools in two neighborhoods in the metropolitan area of Palermo, Italy to experimentally demonstrate that the historical informal institution of organized crime can undermine current institutions, even in religiously and ethnically homogeneous populations. Using trust and prisoner's dilemma games, we found that students in a neighborhood with high Mafia involvement exhibit lower generalized trust and trustworthiness, but higher in-group favoritism, with punishment norms failing to resolve these deficits. Our study suggests that a culture of organized crime can affect adolescent norms and attitudes that might support a vicious cycle of in-group favoritism and crime that in turn hinders economic development.

JEL Classification: C91, C92

Keywords: $\quad$ organized crime, trust, in-group favoritism, Mafia

Corresponding author:

Lamar Pierce

Washington University in St. Louis

Olin Business School

One Brookings Drive Box 1133

Saint Louis, MO 63130

USA

E-mail: pierce@wustl.edu

\footnotetext{
* We thank Ray Fisman, Lorenz Goette, Benedikt Herrmann, Robert Prentice, Matthias Sutter, Richard Zeckhauser, and participants at seminars at UCSD, UT Austin, and the conference of Swiss Economists Abroad. Funding was provided by the Don and Sybil Harrington Foundation and the McCombs School of Business at UT Austin.
} 
Trust towards strangers is critical for facilitating the exchange that leads to economic development and prosperity. ${ }^{1}$ Formal institutions like rule of law, property rights, or the integration of ethnic groups have been argued to be the key to facilitating both trust outside narrow groups and clans as well as economic growth and development (North, 1990; Henrich et al., 2001; Frey and Bohnet, 1995; Bohnet and Huck, 2004). Yet even within countries with common institutions, we observe regional differences in both general trust and in-group favoritism. Italy, for example, has wellknown regional differences in trust between the South and the North (Banfield, 1958; Putnam et al., 1994; Guiso et al., 2006; Bigoni et al., 2013). Similar within-country variation in trust has been documented in Africa (Nunn and Wantchekon, 2011), Europe (Tabellini, 2010; Dohmen et al., 2012), and Israel (Fershtman and Gneezy, 2001). While formal institutions cannot explain these regional differences, they may be attributable to historically-persistent informal or social institutions linked to regional culture (Tabellini, 2010; Greif and Iyigun, 2013). Yet isolating the relationship between specific informal institutions and local variation in trust remains elusive. The core challenge is that even within national boundaries, regions may differ on numerous dimensions that might impact trust, including religion, language, ethnicity, economic wealth, and multiple formal and informal local institutions.

In this paper, we directly address this challenge by studying one of the most globally important informal institutions in a region with common formal institutions and nearly uniform population demographics. We examine how the specific informal institution of organized crime is tied to low general trust and in-group favoritism by conducting behavioral experiments among high school students in the Palermo metropolitan area in Sicily. We exploit a natural experiment in which one of two neighborhoods in the Palermo metropolitan area that had similarly high levels of organized crime thirty years

\footnotetext{
${ }^{1}$ See Algan and Cahuc (2013) for a review of the link between trust and economic growth.
} 
ago saw a dramatic drop over one generation in the dominant informal institution: the Sicilian Mafia. The shock to Mafia involvement in the central Palermo neighborhood resulted from the Italian government's response to the Mafia's assassination of multiple high-ranking officials in Palermo during the 1980's. The government increased police and judicial focus toward the Mafia, locating two major anti-Mafia institutions in a central Palermo neighborhood to be near other government buildings. This locational choice effectively stymied organized crime activity in the neighborhood. In comparison, another neighborhood, Bagheria received no change and thus persisted in its high level of organized crime. ${ }^{2}$

We compare the extent of trust and in-group favoritism in the two Palermo neighborhoods by conducting experiments in high schools located in either the high- or the low-Mafia area. Our adolescent participants $(\mathrm{N}=460)$ played standardized experimental games (trust and prisoner's dilemma games with and without third-party punishment), all with anonymous partners from either their class (in-group) or another class in their school (out-group). ${ }^{3}$

The benefits of studying this setting are threefold. First, the Palermo metropolitan area is characterized by relative uniformity in ethnicity, religion, language, and wealth levels, as well as by extremely low levels of inter-neighborhood migration. This is in contrast to prior studies of regions within countries, which often have different local institutions, dialects, religions, and wealth levels that might also explain variation in trust (Nunn and Wantchekon, 2011; Tabellini, 2010; Bigoni et al., 2013). Our comparison of experimentally-measured trust levels across neighborhoods in the same city is closest to recent work by Falk and Zehnder (2013). Second, our use of experimental

\footnotetext{
${ }^{2}$ This shock is similar to the Buenos Aires Jewish Center bombing used as an exogenous shock to policing in Di Tella and Schargrodsky (2004).

${ }^{3} \mathrm{~A}$ growing number of papers study the influence of the distinction between in- and out-group on economic behavior experimentally (e.g., Charness et al., 2007; Sutter, 2009; Chen and Li, 2009; Goette et al., 2006, 2012a; Falk and Zehnder, 2013).
} 
games allows us to decompose the different elements of trust that are inseparable in survey-based measures of trust (Sapienza et al., 2013). ${ }^{4}$ Although the Sicilian Mafia's culture of low trust toward institutions and outsiders has been widely discussed in political science, sociology, and economics (Gambetta, 1993; Bandiera, 2003; Varese, 2011), we provide behavioral evidence of organized crime's relationship to trust and cooperation. Our experimental approach also allows us to examine the in-group favoritism and parochialism that is both common in organized crime and believed to foster intense intergroup war and violence (Choi and Bowles, 2007; Bowles, 2008; Fershtman and Gneezy, 2001; Gneezy and Fessler, 2012) and constrain economic development (Banfield, 1958; Putnam et al., 1994; Knack and Keefer, 1997; Greif and Tabellini, 2010). Third, organized crime is among the most economically impactful informal institutions in the world. Given estimates that organized crime generates almost $\$ 1$ trillion per year worldwide, or nearly $2 \%$ of global GDP (on Drugs and Crime, 2010), it is important to explore how a culture of organized crime changes the behavioral norms and attitudes of those exposed to it.

We find substantial differences in trust across the two neighborhoods. Students in the high-Mafia neighborhood show lower average trust and trustworthiness levels, and are less likely to cooperate in prisoner's dilemma games than students in lowMafia areas. This cannot be due to differences in general generosity (Ashraf et al., 2006), since non-strategic dictator games show no differences across the neighborhoods. Furthermore, students in high-Mafia neighborhoods show much stronger patterns of in-group favoritism, transferring higher levels to classmates than to those from other classes. Growing up in a culture of crime therefore seems to reduce general trust, and instead bias trust toward in-group members.

Our results also show that while introducing a norm enforcement mechanism can

\footnotetext{
${ }^{4}$ We also use the World Values questions on trust to show similar results.
} 
increase cooperation in both high- and low- Mafia areas, as in Fehr and Gächter (2000), adding a punishment mechanism fails to remediate the difference in trust between the two areas. More importantly, adding a punishment mechanism greatly intensifies the in-group favoritism in high-Mafia schools while it actually reduces it in low-Mafia schools. As such, the informal institution of norm enforcement can exaggerate the negative consequences, in-group favoritism, of another informal institution - organized crime. While in a number of cultures and situations the informal institution of norm enforcement turns out to be anti-social and ineffective (Herrmann et al., 2008; Goette et al., 2012b), our result suggests that norm enforcement can actually negatively interact with other informal institutions, potentially destroying its benefits.

Our results make important contributions to at least three related lines of research. First, we contribute to the growing literature on how culture affects norms and values. For a long time, economists took norms and values as exogenous primitives, studied their implications, and left the analysis of the endogenous evolution of norms and preferences to sociologists. Only recently, there has been a shift in economics towards studying the endogeneity of norms and preferences to their environment (see Bowles, 1998, for an excellent overview). Tabellini (2008), for example, shows that traditional economic methods allow the study of the evolution of norms and values, modeling how cooperation and in-group favoritism can be culturally shaped through parents' choice of what values to transmit to their children. Similarly, recent experimental work by Voors et al. (2012) shows that shocks from conflict in Burundi can impact preferences on risk, time discounting, and altruism. ${ }^{5}$ We provide empirical evidence consistent with endogenous norms and values and show that other cultural and environmental factors such as informal institutions can also shape the norms and values surrounding trust. A

\footnotetext{
${ }^{5}$ For other work on preference evolution and endogenous trustworthiness, see, e.g. Bohnet and Huck (2004); Gueth et al. (2009). Other models of endogenous preferences show additional channels (see Fehr and Hoff, 2011, for an overview).
} 
culture of organized crime seems to be associated with the necessary uncertainty that has been argued by Kollock (1994) to change the norms that are consequentially applied in our anonymous, one-shot experimental setup. Additionally, our evidence from an adolescent population reinforces the notion that early childhood environments have long-term consequences which go far beyond cognitive dimensions to the broader norms and skills necessary for a functional society (Heckman, 2006). The known importance of the development of trust and in-group favoritism in childhood and adolescence (Sutter and Kocher, 2007; Fehr et al., 2008; Algan et al., 2013; Fehr et al., 2013) makes the influence of cultural factors for this population an even more relevant result.

Second, this paper provides empirical evidence on the deleterious effects of low trust and in-group favoritism. Many countries appear to be trapped in conditions of low economic development sustained by low trust and high in-group bias (Putnam et al., 1994), while others exhibit generalized trust and economic growth. Such variation in how people trust strangers across countries and regions (Algan and Cahuc, 2010; Bohnet et al., 2008; Fershtman and Gneezy, 2001; Nunn and Wantchekon, 2011) cannot be explained by evolutionary theories that argue that in-group favoritism is rooted in the inherent psychology of humans, since altruism, reciprocity, and trust are all crucial for the coordination necessary for survival (Bowles, 2008). Formal institutions certainly explain many differences across countries and regions (Aghion et al., n.d.), but our results indicate that informal institutions also play a critical role. This is not to say that we can show a causal effect of organized crime on trust. In fact, a low trust environment is a perfect breeding ground for organized crime. Our results suggest why it is so difficult to escape this trap - organized crime affects trust which affects organized crime, etc., through the reinforcement of generalized mistrust and in-group favoritism. Such a vicious cycle is very difficult to break. However, our results also show that there is hope to break the cycle. The center of Palermo saw a dramatic 
drop in organized crime due to heavy-handed intervention by the Italian government. Teenagers who grew up in this lower Mafia involvement environment start to trust more and show less detrimental in-group favoritism or parochialism. Those same trusting norms will make it harder for organized crime to re-establish itself. This might be the path to a new and better equilibrium.

Third, our results contribute to the literature on organized crime. While there is a large literature on the economics of individual criminal activity (going back to Becker (1968)), only a few studies examine organized crime (for reviews, see, e.g., Fiorentini and Peltzman, 1997; Kumar and Skaperdas, 2009). These studies analyze the origin of the Mafia (Gambetta, 1993; Bandiera, 2003), the functioning of crime organizations (e.g., Baccara and Bar-Issac, 2008; Levitt and Venkatesh, 2000; Leeson, 2007) or try to calculate the economic costs of organized crime and terrorism (e.g., Abadie and Gardeazabal, 2003; Pinotti, 2012; Frey et al., 2007). To our knowledge, there is little to no empirical evidence highlighting the behavioral effects of a culture of organized crime. The only exception is recent work by Nese et al. (2013), who use experiments to compare prison inmates affiliated with organized crime to university students. Our evidence that a culture of organized crime is associated with low trust and high ingroup favoritism is consistent with substantial indirect effects of organized crime, as lower trust and more in-group bias affect even those aspects of economic activities not directly involving organized crime. As such, measuring the direct cost of organized crime most likely underestimates its detrimental effect on society if behavioral effects are left out.

We note that like all cross-cultural studies, we must be careful in interpreting any relationship between Mafia culture and student behavior as causal. Although our historical shock to the central Palermo neighborhood is plausibly exogenous, we cannot rule out some underlying pre-existing differences before this shock. Where our setting 
excels is in the remarkable similarity on other dimensions between the populations in the neighborhoods. Compared to prior studies, the demographic homogeneity in our three schools is remarkable.

While experimental studies such as ours would ideally involve more than two neighborhoods and three schools, we note that the conditions for explicitly studying the Mafia in Sicilian schools are exceptionally difficult. Schools in Palermo are reluctant to allow researchers to study organized crime, given safety concerns for the staff, students, and researchers. Although our studies were carefully designed to protect the anonymity of students, the researcher conducting the studies was not anonymous, and in one instance was confronted and warned by a teacher presumably connected with the Mafia.

The remainder of the paper is organized as follows. In Section 1 we explain the history of organized crime in Palermo, as well as the recent shock that impacted the culture of one neighborhood. Sections 2 and 3 present the experimental designs and results. Section 4 provides robustness tests. Section 5 concludes.

\section{The Mafia and Its History in Two Palermo Neighborhoods}

The Sicilian Mafia is a strong informal institution that governs everyday life. Although its origins can be traced back to at least the end of the 18th century, the term Mafia ("maffia") appeared for the first time in an 1865 Italian government document, when the Prefetto Filippo Antonio Gualterio (the "Prefetto" is the Italian government representative in a province) wrote a letter to the Minister of Internal Affairs mentioning

the existence of a criminal organization located in Sicily (Santino, 2000). It emerged as a protection mechanism when Southern Italy had weak formal institutions (Gam- 
betta, 1993) incapable of enforcing property rights. Sicily, like most of Southern Italy, consisted of clan-like communities whose low social capital developed through a history of occupation and poverty (Banfield, 1958; Putnam et al., 1994; Guiso et al., 2006). Unable to trust institutions or outsiders, Sicilians bought protection through association with local Mafia clans (Gambetta, 1993; Bandiera, 2003; Buonanno et al., 2012). Despite the rapid economic development of Italy during the late 20th century that brought much stronger Italian and European institutions capable, at least in theory, of protecting property rights (Gambetta, 1993; Varese, 2011), the Mafia (as well as its counterparts elsewhere in Italy) has continued to thrive and grow economically.

Today, the Mafia has a direct or indirect influence on economic activity not just in Sicily, but in the whole Italian peninsula and North America, with similar organized crime networks in other regions of Italy (e.g., Camorra in Naples) and around the world (e.g., Japanese Yakuza, Russian Mafia, Chinese Triad) (see, e.g., Varese, 2011). The Province of Palermo and, in particular, the metropolitan area of Palermo, has been characterized over the last century by very strong and stable control by Mafia families who imposed their rule on all significant economic and social activities (Commissione Parlamentare d'Inchiesta sul Fenomeno della Criminalita Mafiosa o Similare, Relazione Annuale, 2003).

The Italian government's aggressive response to a series of Mafia murders, however, produced heterogeneous shocks to Mafia culture across the Palermo metropolitan area. In 1980, Piersanti Mattarella, president of the region, was assassinated by the Mafia. In 1982, General Dalla Chiesa, appointed prefect to fight the Mafia, was killed less than 200 meters from the central Palermo school in our study, followed by Mafia assassinations of Rocco Chinnici (anti-Mafia judge) in 1983 and Ninni Cassara (police manager) in $1985 .{ }^{6}$ The Italian government responded in two ways. First, it increased the num-

\footnotetext{
${ }^{6}$ These are only a few examples of a much larger set of murders associated with the Mafia.
} 
ber of police, carabinieri, and judges focused exclusively on the Mafia, concentrating their activities in the center of Palermo. Second, it created two new institutions in the center of Palermo to fight the Mafia: Direzione Investigativa AntiMafia and the Direzione Nationale AntiMafia. Following the assassination in 1992 of two very important judges, Giovanni Falcone and Paolo Borsellino, combined with the enhanced anti-Mafia efforts, a critical mass of anti-Mafia activists emerged in the center of Palermo, shaping a new anti-Mafia culture. ${ }^{7}$

This institutional shock to central Palermo created sharp cultural differences between it and surrounding neighborhoods. Even though the center of Palermo is less than $15 \mathrm{~km}$ from the town of Bagheria, the two areas are extremely different in terms of Mafia-related attitudes. For example, in 2004, one of the most influential anti-Mafia organizations, Addiopizzo, was founded in the center of Palermo in order to build a community of businesses and consumers who refuse to pay "pizzo" - Mafia extortion money (Vaccaro, 2012). At the time of the study, more than 90\% (over 400) of the firms participating in the initiative are located in the center of Palermo, while only $4 \%$ are in Bagheria (despite Addiopizzo devoting considerable energy toward Bagheria). ${ }^{8}$ In addition, many criminals collaborating with police authorities confirm that the Mafia still controls nearly every kind of activity in Bagheria, with much less power in the center of Palermo. ${ }^{9}$ Interviews with anti-Mafia experts, teachers and principals of the three schools confirmed this substantial difference between the two areas (see Table 1).

Thus, students enrolled in the schools in the two neighborhoods are exposed to

\footnotetext{
${ }^{7}$ This history is based on extensive interviews with local police organizations and leaders of the anti-Mafia organization Addiopizzo.

${ }^{8}$ Since then, the number of certified shops in central Palermo has grown to 800, while the count in Bagheria has not changed. Although central Palermo has more firms in total than Bagheria, proportionally there are still more certified shops in central Palermo.

${ }^{9}$ Furthermore, both police and journalists believe Bagheria to be so pro-Mafia as to harbor the fugitive Mafia boss Matteo Messina Denaro, one of the most notorious Mafia leaders. See http://archivio.antiMafiaduemila.com/rassegna-stampa/30-news/13404-matteo-messina-denaroprotetto-a-bagheria-la-citta-di-provenzano.html?start $=1$.
} 
Table 1: Exposure to Mafia Activities Judged by Experts

\begin{tabular}{lcc}
\hline & Bagheria & Palermo \\
\hline Ratings of School Mafia Involvement by School Administrators & $7(6)$ & $2(3)$ \\
Ratings of School Mafia Involvement by Teachers & $6.9(16)$ & $2.3(8)$ \\
Ratings of Neighborhood Mafia Involvement by Experts at Ad- & $7(4)$ & $1.5(4)$ \\
diopizzo (Anti-Mafia Organization) & & \\
Number of Stores Adopting Addiopizzo Anti-Mafia Certificate & 7 & 403 \\
within 5km & & \\
\hline
\end{tabular}

Notes: Experts are asked to rate the Mafia involvement on a 7-point scale with 7 indicating high involvement. Numbers in parenthesis are number of respondents. Addiopizzo numbers reflect the time period of the study (January, 2012), with the gap between the two neighborhoods growing since then.

very different informal institutions: in the center of Palermo they are exposed to a predominantly anti-Mafia culture (both inside and outside of the school), while students attending schools in Bagheria live in a context that is more supportive toward the Mafia. In the survey that we administered following the experiments, students were asked a series of questions on attitudes toward the Mafia (see questionnaire in Appendix F). As can be seen in Table 2 the answers were consistent with a higher Mafia involvement in Bagheria than in Palermo - even though it is very likely that students expressed fear of revealing their true attitudes to the researchers. On a seven-point or three-point scale, the Bagheria schools tended to report greater impact from the Mafia as well as more positive views. ${ }^{10}$

\footnotetext{
${ }^{10}$ These questions correspond with Questions 21f, 23, 21d, 22, 21e in the survey in Appendix F. Question 23 was recoded to be ordinal. Questions 24 and 25 were not included in the analysis because they were only asked to students in central Palermo after receiving low response rates for question $21 \mathrm{~d}$.
} 
Table 2: Students' Attitudes Towards Mafia

\begin{tabular}{lccc}
\hline & $\begin{array}{c}\text { Bagheria } \\
\text { (High-Mafia) }\end{array}$ & $\begin{array}{c}\text { Palermo } \\
\text { (Low-Mafia) }\end{array}$ & $\begin{array}{c}p \text {-value of } \\
t \text {-test }\end{array}$ \\
\hline $\begin{array}{lcc}\text { Mafia has positive impact on society (1 to 7) } \\
\text { Mafia influences environment where you live }\end{array}$ & $\begin{array}{c}1.67(0.08) \\
\text { (1 to 3) }\end{array}$ & $1.35(0.067)$ & 0.003 \\
Mafia is on the wrong side (1 to 7) & $6.32(0.09)$ & $6.67(0.13)$ & 0.096 \\
$\begin{array}{l}\text { Mafia impact on friends and family (1=Pos- } \\
\text { itive, 3=Negative) }\end{array}$ & $1.28(0.03)$ & $1.44(0.04)$ & 0.001 \\
$\begin{array}{l}\text { Mafia substitutes for the state because it pro- } \\
\text { vides security to people (1 to 7) }\end{array}$ & $1.77(0.09)$ & $1.89(0.11)$ & 0.438 \\
\hline \# of students & 257 & & \\
\hline
\end{tabular}

Notes: Means and standard errors in parenthesis. Students respond to the statements/questions (in Appendix F) using either a 7-point scale from 1 "strongly disagree" to 7 "strongly agree" or a 3-point scale. Question 23 was recoded to be ordinal. Many students (139) refused to answer the question about the Mafia being on the wrong side.

\section{Set-up and Design of Study}

\section{$2.1 \quad$ Set-up and Subjects}

\subsubsection{School and Area Characteristics}

We selected schools that were in areas in the metropolitan area of Palermo that differ starkly in the local population's support for the Mafia. Our schools are located in Bagheria (two schools) and in the center of Palermo (one school). All schools are public high schools that use similar syllabi with similar teaching objectives. An experienced high school teacher who had worked for the Italian Ministry of Education in the Province of Palermo for more than 35 years helped us select three schools with very similar curricula, whose administration all agreed to participate in the study. The Palermo school has a completely identical curriculum to one of the Bagheria schools, with 9 core courses in Italian, Math, History and Philosophy, English, Sport, Religion, 
Sciences, History of Art, and Latin and Greek. The other Bagheria school shares the first six courses, but replaces the last three with additional technical and scientific coursework.

All classes were from the final 3-year cycle of high school (the "triennio") and were of similar size. Students in these schools are assigned to classes in their first year in a quasi-random fashion, with a few exceptions made to avoid any concentration of minority students. Students then stay in these classes for five years. Within each school, there seem to be no notable differences across classrooms in observable characteristics other than age (because of grade level) and average grades. The study was particularly designed to ensure the complete anonymity and safety of the students, given past patterns of severe violence in the student population. The study was approved by the Sicilian Ministry of Education as well as the principals of all three schools. All students signed consent forms.

The three schools are located respectively in the center of Palermo and in the center of Bagheria. All of them are part of the Palermo metropolitan area - an area that is highly integrated and with very similar socio-economic conditions. The driving distance between the two neighborhoods is approximately $14 \mathrm{~km}$, and as Figure 1 shows, they are connected by metropolitan rail and bus system. ${ }^{11}$ Table 3 shows useful demographics that characterize the areas of the three schools.

\subsubsection{Student Characteristics}

Within the schools, we randomly chose 22 classes that were in the last three years of high school. The reasons for focusing on later cohorts of high school students are threefold: First, they would have less difficulty in understanding and playing the games; second, most of them were directly exposed to the social norms of the local society;

\footnotetext{
${ }^{11}$ See the regional law (Legge Regionale 9/1986) and the Regional Ordinance (Decreto Presidente Regione 10/8/1995) for more details.
} 


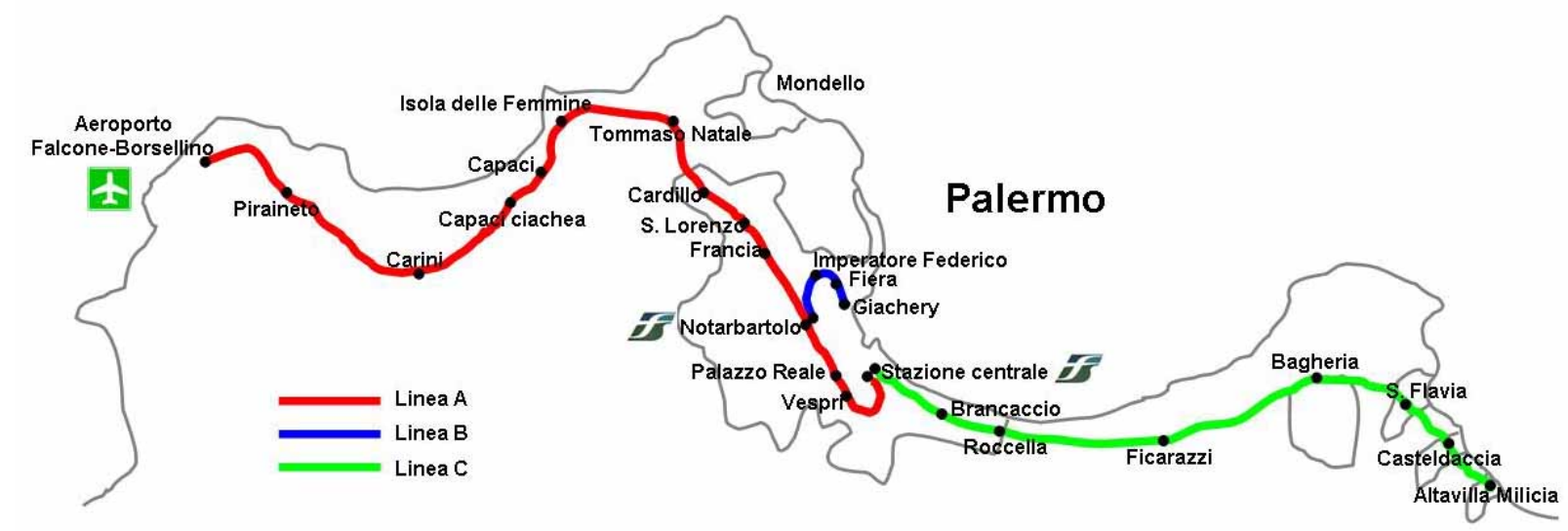

Figure 1: Palermo Metropolitan Rail System. The central Palermo school is located near the "Notarbartolo" station.

Table 3: Area Characteristics

\begin{tabular}{lcc}
\hline & Palermo & Bagheria \\
\hline Male & 47.4 & 48.6 \\
Female & 52.6 & 51.4 \\
Average age & 40.4 & 38.9 \\
Population variation (internal migration) 2010 & -0.0011 & 0.0038233 \\
Percentage of population aged 15-19 & $6.60 \%$ & $6.70 \%$ \\
Average population density where the students live (per km2) & 4120 & $3837.25^{a}$ \\
Salary per capita (€/year) & 14345 & 17710 \\
Average no. of members per family & 2.52 & 2.81 \\
\hline
\end{tabular}

Notes: Information is from the Italian Statistical Association ISTAT, 2011.

${ }^{a}$ Numbers for Bagheria are calculated and weighted considering that $35 \%$ of the student population live in the Villabate area, $35 \%$ in the Ficarazzi area and 30\% in the Bagheria area. Palermo numbers reflect Palermo city.

and third, they would be more capable of taking part in such a long experiment.

The two sets of schools and the subjects in the high- and low-Mafia area have very similar socio-demographic characteristics, with all students being native-born Italians. Table 4 shows descriptive statistics of socio-demographic variables for the two set of schools. It also shows statistics of two-sided $t$-tests or Fisher's exact tests for differences in any of the characteristics. The two demographic differences between the two sets of 
schools are religion and age. Religious differences are extremely minor, compared with other cross-cultural studies, since all students were born in Italy and nearly all were born and baptized Catholic. The minor difference is that students in the high-Mafia area are more likely to self-identify as Catholic and to attend church, although the implications of these differences from prior work are unclear. Although La Porta et al. (1997) found that individuals in Catholic countries self-reported lower trust than others, more recent experimental work finds greater fairness for individuals associated with world religions (Norenzayan and Shariff, 2008; Henrich et al., 2010). Differences in age could matter as trust develops in adolescence (e.g. Sutter and Kocher, 2007) which would bias our results against finding lower trust in low-Mafia school. Older students could, however, also have stronger group identity because they had been together longer. The slightly higher number of siblings in the high-Mafia neighborhood likely biases against our results. Cameron et al. (2013) found lower trust among single children by exploiting the discontinuous drop in siblings following China's one-child policy implementation. Regardless, supplemental analysis, which will be explained in detail below, shows that these differences are highly unlikely to explain our results. Including age, religion, and numerous other control variables in regression analyses does not change our results, nor does restricting our sample to only students across the common data support of age or religion.

While all the students from the high-Mafia Bagheria schools were local, 82 of the central Palermo students do not live in the immediate vicinity, but instead commute in from surrounding neighborhoods in the metropolitan area (none live in Bagheria). According to the school vice-principal, these commuting students spend the vast majority of their time in the center of Palermo, including school, sports, and social activities. Although these commuting students are still likely affected by the local neighborhood culture, we compared only the 105 local students to the 257 students from the two 
Bagheria schools. Results for the trust game remain unchanged, although the differences in the prisoner's dilemma games weaken in statistical significance. We will discuss these results in section 4.2 .

The other major difference in the student population between the two sets of schools is gender distribution. Although the low-Mafia school has a relatively equal gender distribution with 38 percent male, the high-Mafia schools are highly segregated. One school is only 20 percent male, while the other includes only males. While the combined data from the two high-Mafia schools allow us to effectively rule out gender as explaining our results, we are concerned that gender segregation might confound our conclusions. We will present robustness checks in section 4.3 to address gender segregation as an explanation for our findings.

\subsection{Experimental Design}

\subsubsection{Games and In-Out-Group Manipulation}

Participants played the following games in the same order (see Appendix G for translated instructions):

1. Trust: Participants made the decision of the first mover in a standard trust game (Berg et al., 1995). They received $€ 1$ as endowment and had to decide how much to pass in increments of 10 cents to an anonymous partner. The amount was tripled on the way. The amount passed to the anonymous partner is called "trust" in the paper.

2. Trustworthiness: Participants then made decisions as the second mover with a different partner. Using the strategy method (e.g., Brandts and Charness, 2011) they decided for each amount they could receive from a first-mover partner how 
Table 4: Socio-demographic Characteristics of Students

\begin{tabular}{lccc}
\hline & High-Mafia School & Low-Mafia Schools & $\begin{array}{c}p \text {-value of } \\
\text { test }^{a}\end{array}$ \\
\hline Birth Year & 1993.2 & 1994.0 & 0.000 \\
Catholic $^{b}$ & $(0.06)$ & $(0.06)$ & \\
Attend church $^{b}$ & 0.86 & 0.75 & 0.01 \\
Male $^{b}$ & 0.35 & 0.21 & 0.001 \\
\# of cars & 0.45 & 0.38 & 0.17 \\
\# older siblings & 2.05 & 2.07 & 0.75 \\
\# younger siblings & $(0.06)$ & $(0.06)$ & 0.86 \\
\# of kins in house & 0.74 & 0.72 & 0.01 \\
Grades & $(0.07)$ & $(0.06)$ & 0.34 \\
Allowance & 0.77 & $(0.05)$ & \\
& $(0.05)$ & 0.14 & 0.81 \\
\hline No. of participants & 0.21 & $(0.04)$ & \\
\hline
\end{tabular}

Notes: Means and standard errors in parenthesis. ${ }^{a} t$-tests for continuous variables and Fisher's exact tests for dummy variables. ${ }^{b}$ Dummy variables.

much they would return to that partner. We take the average amount returned for all possible first mover transfers and call it "trustworthiness" in the paper.

3. Prisoner's Dilemma: Participants then played a one-shot, simultaneous prisoner's dilemma game with a new partner. Both players were endowed with $€ 1$ and had to decide whether to pass the endowment to an anonymous partner or keep it. The amount passed was doubled on the way.

4. Third-Party Punishment: Participants then had to decide whether to punish participants in a prisoner's dilemma (Fehr and Fischbacher, 2004; Goette et al., 2012b). They were endowed with $€ 0.9$ and decided how much money to deduct 
from a new randomly-assigned player in a prisoner's dilemma. Each deduction point cost the punisher 1 while costing the punished party 3 . The players indicated for each potential action of the players in the prisoner's dilemma how much deduction points they would assign (strategy method). Participants knew that the deduction points would apply to a new prisoner's dilemma to be played next.

5. Prisoner's Dilemma with Third-Party Punishment: Participants then played a prisoner's dilemma game as before but now were punished by a randomly-assigned third-party, based on both their action and the decision of the third party punisher in the previous decision.

6. Dictator Game: Participants played a dictator game in which they were endowed with $€ 1$ and could give up to that amount in increments of 10 cents to an anonymous partner.

For the in- and out-group manipulation, we randomly assigned half of the classrooms to a condition where they interacted with another person from the same class (in-group condition), while the other half were assigned to interact with a participant from another class but within the same school (out-group condition). Therefore, students played either in-group or out-group versions of the games.

\subsubsection{Procedures}

The neutrally framed experiments were run between December 2011 and January 2012 and were conducted by the same researcher, who is a native of Sicily. All experiments were conducted using paper-and-pencil in the room where each class conducts its normal educational activities. The researcher took great care to ensure the anonymity of the participants. We informed the students at the beginning of the session about the steps to protect their anonymity. Students were dispersed throughout the rooms 
to ensure answers were not visible to others. Students were prohibited from speaking before, during, or immediately after the game. Participants were paid within 15 days with sealed envelopes, using an unique identifier that only the student knew. Average payments were $6.99 €$ in Bagheria and $7.84 €$ in central Palermo. The vice-principals who delivered the envelopes specifically watched for any bullying or confrontation, but did not observe any, nor was there any bullying reported by students, teachers, or parents following the experiment. The experiments lasted between 90 and 120 minutes. All students voluntarily decided to participate in the experiments. After all the experiments were completed, participants filled out a short questionnaire (see Appendix $\mathrm{F})$.

To ensure students understood the instructions, we implemented a number of steps. Prior to the studies, we confirmed with several teachers at each school that students would be able to understand them. In conducting the studies, each experiment was explained at least three times, and after the explanation, the students performed several trial runs, after which they were given the opportunity to ask more questions. The game was conducted only when all the students said that they understood the rules. At the beginning of each game, the instructor stated clearly that the outcome of each game was independent of the outcome of the previous games and that for each game, each student would interact with a different person. To calculate participants' payoff, for each game we randomly matched participants to a partner - from the same class or from another class depending on the treatment. While in experiments one can never completely rule out that misunderstanding affected the behavior of participants, our procedures were carefully designed to maximize students' understanding. Furthermore, we don't believe issues of understanding would affect differences between our treatments and differences between high- and low-Mafia areas. 


\section{Results}

The results are presented in two steps: First, we discuss behavioral differences in the different economic games between high- and low-Mafia schools across both in- and outgroup treatments. Second, we investigate the difference between behavior towards inand out-group members.

\subsection{Trust and Trustworthiness}

Panel A in Figure 2 shows the mean transfer levels for the trust game separated by the neighborhood of the school (low-Mafia vs. high-Mafia). The average trust levels (i.e., transfers by Player X) are considerably lower in the high-Mafia schools (€0.389), than in the low-Mafia schools $(€ 0.552)$ (t-test; $p<.001)$. Similarly, the average amounts returned by Player Y, across all possibilities, are lower in the high-Mafia schools (response functions are also different, see the figure in the Appendix B). Students in Bagheria returned only $€ 0.481$, compared to $€ 0.576$ in central Palermo $(p<.01)$. These results suggest that on average, students in the high-Mafia schools demonstrate lower levels of trust as well as less trustworthiness and reciprocity. Student responses from the survey conducted following all the experiments support these results. ${ }^{12}$ Importantly, the mean transfers in the dictator game were nearly identical across schools $(€ 0.327$ for high-Mafia vs. €0.313 for low-Mafia), suggesting that neither altruism nor generosity are driving the general trust results.

To put the magnitude of our trust result in perspective, one could compare our trust differences across neighborhoods to the results in Falk and Zehnder (2013), who find that the average difference in trust between the most and least trusted district in Zurich is 11 percent. The differences between trust levels in low-Mafia and high-Mafia

\footnotetext{
${ }^{12}$ Using trust questions from the World Values Survey (see Table A1 in the Appendix for details), students in the high-Mafia schools were less trusting of strangers $(p<.01)$ and demonstrated higher levels of mistrust $(p<.05)$.
} 

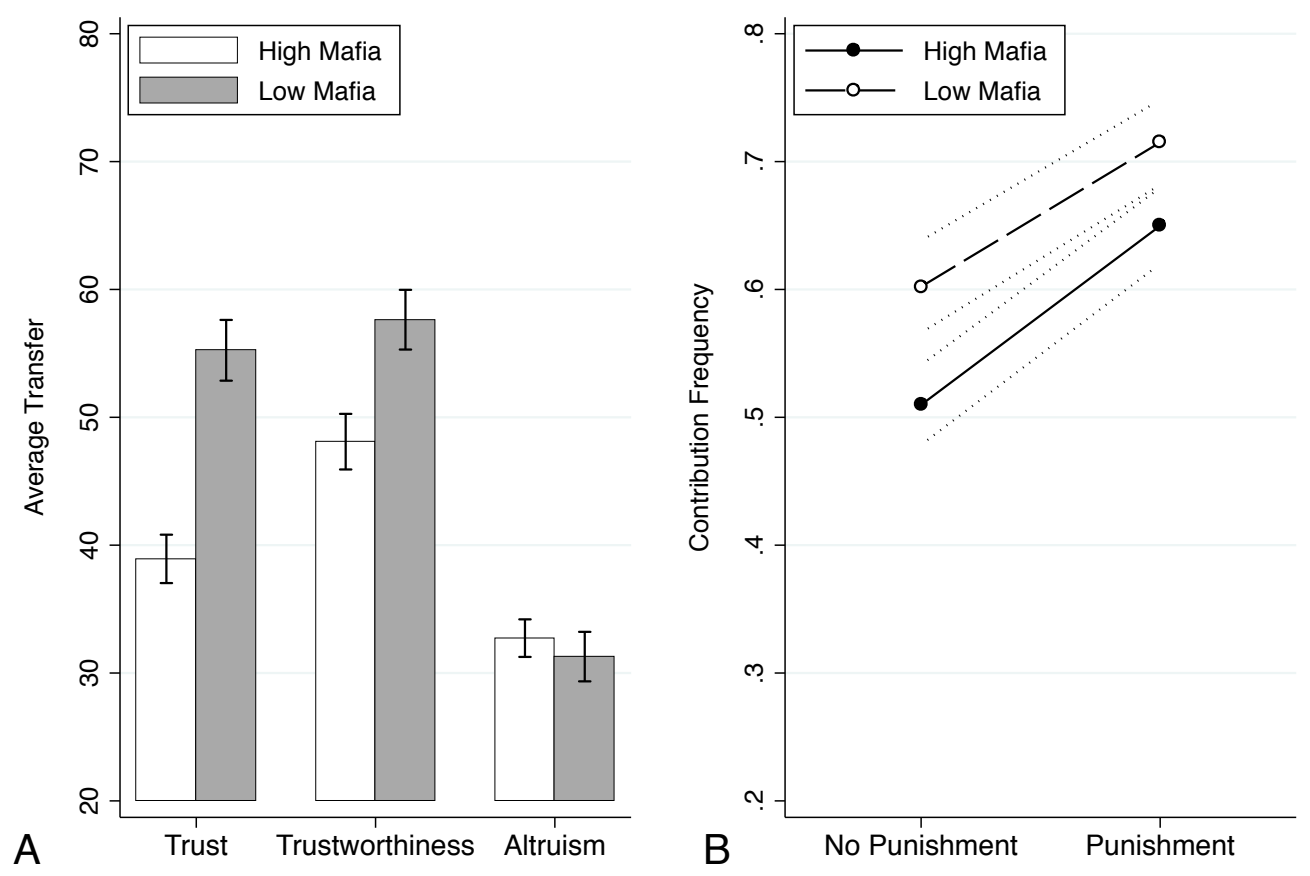

Figure 2: Contributions in the different games for high- and low-Mafia areas. Panel A shows transfers of Player X in the trust game ("Trust") and the average amount returned by Player Y for all possible contributions of Player X ("Trustworthiness"). "Altruism" indicates the transfer in the dictator game. Panel B shows cooperation rates in the prisoner's dilemma without and with punishment possibility. SEM are shown as bars or bands around the means.Data are pooled from both in-group and out-group conditions.

schools are much more pronounced (about 40\%), which could indicate the importance of our results. However, we must keep in mind that the two studies differ in many dimensions.

Panel B of Figure 2 shows the frequency of cooperation in the prisoner's dilemma games for both with and without punishment. Without punishment a smaller percentage of students in the high-Mafia schools (51.0\%) transferred their endowment to their partner than in the low-Mafia school $(60 \%)(p=.054)$, similar to the results in the trust game. Importantly, in both low- and high-Mafia areas, the punishment mechanism in- 
creases cooperation significantly $\left(\chi^{2}(1)=5.27, p=.02 ;\left(\chi^{2}(1)=10.35, p=.001\right)\right.$, with no difference between the two sets of schools $\left(\left(\chi^{2}(2)=0.78, p=.68\right)\right.$. Organized crime therefore seems not to negatively affect the overall effectiveness of a norm enforcement mechanism, but the norm of punishment fails to resolve the underlying trust and cooperation problems associated with organized crime.

Although the demographics of the two neighborhoods are remarkably similar, we are still concerned that differences in student characteristics might be driving our results. Furthermore, we are concerned that class-specific factors might lead to the correlation of error terms within each class, thereby understating our standard errors. To address both these issues, we first regress trust on a dummy indicating the student was at a high-Mafia school as well as different combinations of control variables using ordinary least square (OLS). The goal is to ensure that the negative relationship between Mafia neighborhood and trust observed in Figure 2 is robust to demographic control variables, classroom size, and error terms clustered at the classroom level. ${ }^{13}$ We present these regressions in Columns (1)-(5) in Table 5. While the control variables have little effect on the coefficient of interest, the clustering correction does increase the standard errors from the basic t-tests in Figure 2.

We repeat this process for trustworthiness, the dictator game transfer, and the prisoner's dilemma transfers in Columns (6)-(10) of Table 5. For the trust and dictator games, the dependent variable was the transfer amount. For the prisoners dilemma games our dependent variable was a dummy indicating a transfer. We used an OLS specification for the trust and dictator games, ${ }^{14}$ and show logit coefficients for the prisoner's dilemmas. Similar to the results in Table 5, the inclusion of control variables does not significantly change our parameters, although the standard errors clustered

\footnotetext{
${ }^{13}$ Clustering at the neighborhood level suffer from inference problems detailed in Cameron and Miller (2010).

${ }^{14}$ The results are robust to and better identified in Tobit specifications that account for censoring on both sides.
} 
at the class level decrease their statistical significance. ${ }^{15}$

In sum, the results show that students in the high-Mafia area are less likely to trust and to be trustworthy. ${ }^{16}$ This lower trust is also reflected in lower cooperation rates in the prisoner's dilemma, although these results are weak with clustered errors. These results cannot be due to lower general levels of generosity as we found no difference in dictator game giving. While the possibility to punish defectors increases cooperation rates in high- and low-Mafia schools, the norm enforcement mechanism is not able eliminate the trust difference between the two areas. While these results are based on analysis across group matching, the next section presents differences between behavior towards in- vs. out-group members.

\footnotetext{
${ }^{15}$ See the table in Appendix B for control variable coefficients.

${ }^{16}$ Our results are based on difference between high- and low-Mafia areas within Palermo. We could, however, also have used differences in students' attitudes towards the Mafia. We are reluctant to use those self-reported measures as there is a lot of noise in such measures and substantial demand effect given the sensitive nature of the topic. However, if we would do this analysis (results available on request), the qualitative results mainly hold but are estimated with a lot of noise.
} 


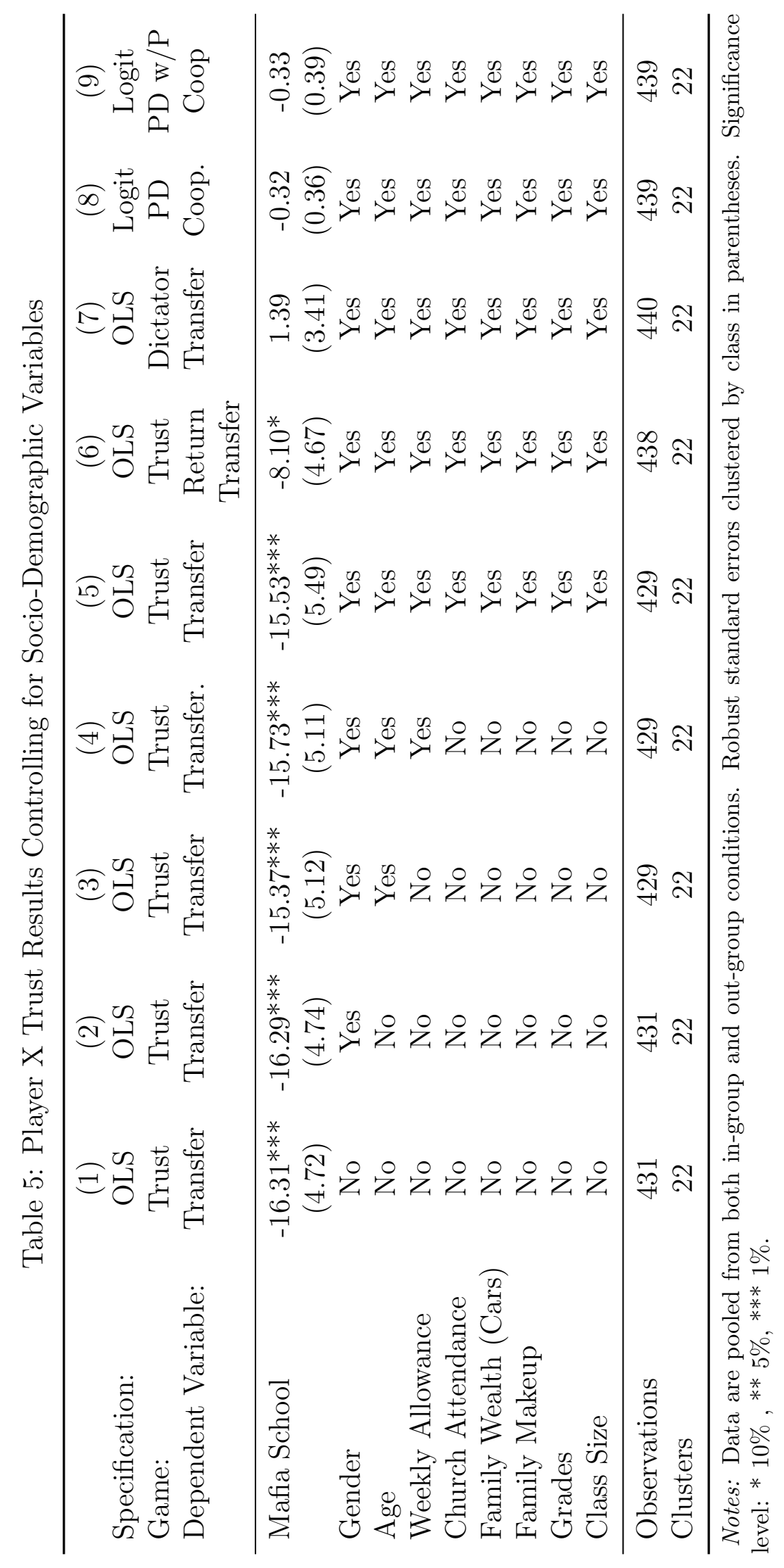




\subsection{In-group favoritism}

Figure 3 presents the extent of in-group favoritism in the different games for the lowand high-Mafia schools. The figure reports in-group favoritism, i.e., the mean difference between transfers and cooperation rates between in-group and out-group conditions. Panel A shows that there are substantial differences in in-group favoritism between the high-Mafia and low-Mafia students. For the high-Mafia schools, students were considerably more trusting of in-group partners than out-group partners (43.67 vs. 34.15, $p=.012$ ). Similarly, as Player Y (i.e., second movers in the trust game), they were more likely to transfer money back to in-group partners (51.94 vs. 44.28 , $p=.078)$. They were also more altruistic toward in-group partners than out-group partners when playing the dictator game (35.98 vs. 29.46, $p=.026)$. This is in stark contrast to students at the low-Mafia school who showed no in-group favoritism in trustworthiness (56.48 vs. $58.82, p=.619$ ) or altruism (30.32 vs. $32.28, p=.613$ ), and exhibited even higher trust levels towards the out-group (50.21 vs. $60.43, p=.031$ ). These results are strongly supportive of enhanced in-group favoritism in the high-Mafia neighborhoods.

Panel B shows that adding a punishment mechanism increases in-group favoritism substantially in the high-Mafia schools. While high-Mafia schools show higher ingroup favoritism in games without punishment, in-group favoritism is not statistically significant either for the high-Mafia or the low-Mafia schools (.535 vs. .484, $p=.418$; .596 vs. $.609, p=.857)$. However, the addition of punishment changes the dynamics in the prisoner's dilemma considerably. In the high-Mafia schools, contributions to ingroup partners rise significantly while those to out-group partners do not (.744 vs. .555, $p=.001)$. In contrast, students in the low-Mafia schools do not significantly increase contributions to in-group partners but actually increase out-group contributions (.621 vs. $.813, p=.004)$. While it is unclear what baseline behavior to expect for this age 

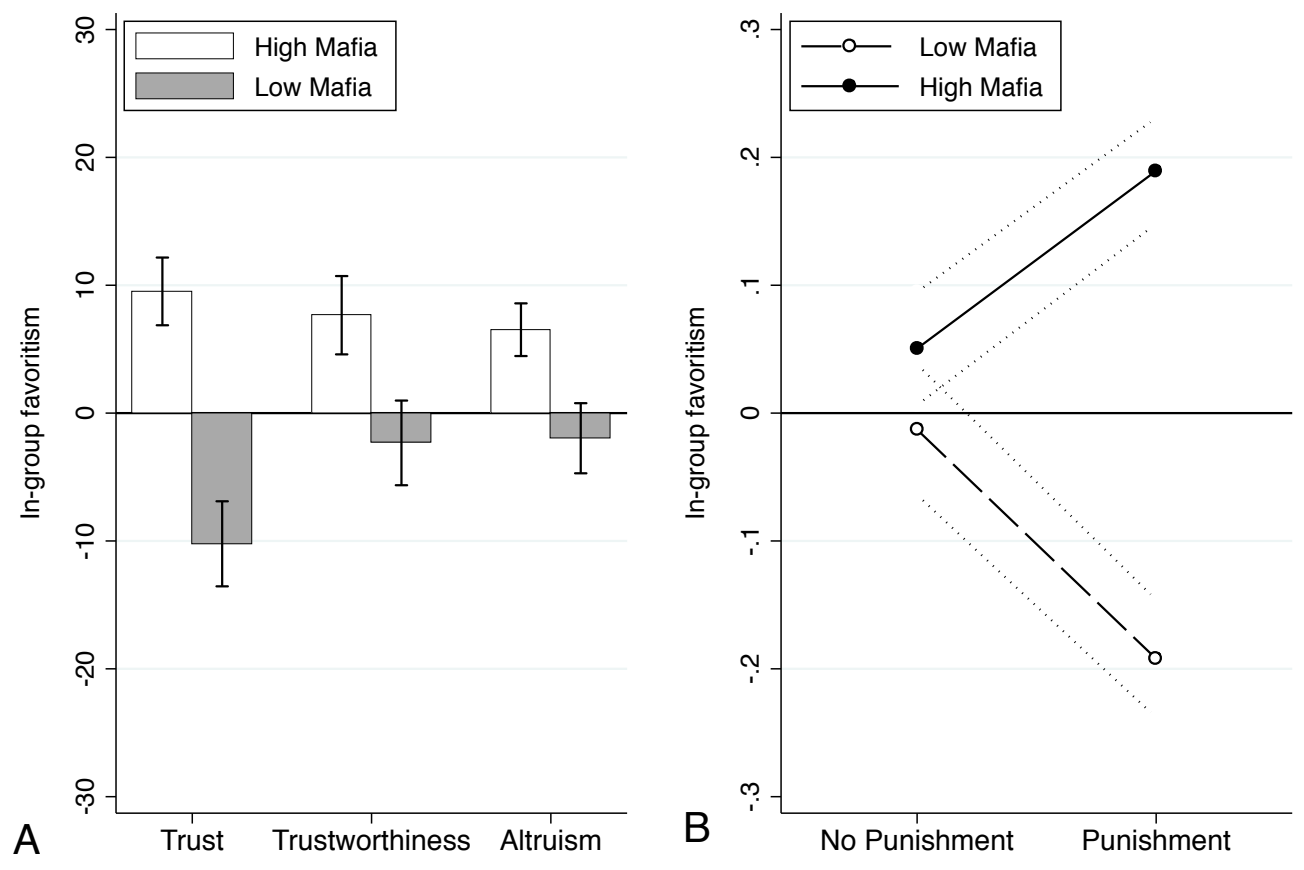

Figure 3: Figure shows difference of transfer or cooperation rate between in-group members and out-group members (in-group favoritism). Panel A shows behavior in the trust game (trust and trustworthiness) and in the dictator game. Panel B shows in-group favoritism in the prisoner's game without and with punishment. SEM are shown as bars or bands around the means. 
group in Italy due to a lack of previous studies in such a setting, the results suggest that in low-Mafia high schools students show some out-group favoritism, possibly due to status consideration (Friesen et al., 2012) or dislike of their own group (Bilewicz and Kofta, 2011).

Table 6 presents regressions that tests the robustness of the results in Figure 2 to adding control variables and standard error clustering at the class level. Table 6 presents OLS specification in which the Mafia neighborhood dummy is interacted with a dummy indicating the in-group condition. These regressions support the results in Figure 2 for trust and cooperation rates in the prisoner's dilemma when norm enforcement is possible. While both approaches show the same qualitative results, clustering at the class level predictably increases the standard errors.

In the prisoner's dilemma games, the specter of punishment clearly evokes in-group favoritism in the high-Mafia neighborhoods. Why might this be the case? The pattern of punishment of defectors, i.e., individuals who did not pass their endowment in the prisoner's dilemma, shows that students in high-Mafia schools punish in-group members at both slightly higher levels and with higher frequencies (see Figure 4 for punishment of defectors. Appendix D shows punishment for all cases). While the in-group favoritism in punishment is not statistically different between the two neighborhoods, this does suggest that the informal institution of organized crime focuses the punishment norm inward in ways that may reduce its efficacy in enforcing broader societal cooperation.

In sum, the results of this section shows that students that grow up in an environment with higher Mafia involvement are more inclined to be in-group biased. The presence of a norm enforcement mechanism exacerbates such in-group favoritism. 
Table 6: Effect of Mafia Involvement Controlling for Socio-Demographic Variables

\begin{tabular}{|c|c|c|c|c|c|}
\hline $\begin{array}{l}\text { Specification: } \\
\text { Game: } \\
\text { Dependent Variable: }\end{array}$ & $\begin{array}{c}(1) \\
\text { OLS } \\
\text { Trust } \\
\text { Transfer }\end{array}$ & $\begin{array}{c}\text { (2) } \\
\text { OLS } \\
\text { Trust } \\
\text { Return } \\
\text { Transfer }\end{array}$ & $\begin{array}{c}(3) \\
\text { OLS } \\
\text { Dictator } \\
\text { Transfer }\end{array}$ & $\begin{array}{c}(4) \\
\text { OLS } \\
\text { PD } \\
\text { Coop. }\end{array}$ & $\begin{array}{c}(5) \\
\text { OLS } \\
\text { PD w/P } \\
\text { Coop. }\end{array}$ \\
\hline Mafia School & $\begin{array}{c}-25.95^{* * *} \\
(5.16)\end{array}$ & $\begin{array}{c}-14.58^{* *} \\
(5.01)\end{array}$ & $\begin{array}{l}-3.10 \\
(3.17)\end{array}$ & $\begin{array}{l}-0.08 \\
(0.09)\end{array}$ & $\begin{array}{c}-0.25^{* * *} \\
(0.05)\end{array}$ \\
\hline In-Group & $\begin{array}{c}-12.59^{*} \\
(6.44)\end{array}$ & $\begin{array}{l}-4.00 \\
(6.67)\end{array}$ & $\begin{array}{l}-3.04 \\
(5.90)\end{array}$ & $\begin{array}{c}0.03 \\
(0.16)\end{array}$ & $\begin{array}{c}-0.22^{*} \\
(0.11)\end{array}$ \\
\hline Mafia $\times$ In-Group & $\begin{array}{c}22.52^{* *} \\
(8.18)\end{array}$ & $\begin{array}{l}13.15 \\
(9.75)\end{array}$ & $\begin{array}{c}9.13 \\
(7.08)\end{array}$ & $\begin{array}{c}0.01 \\
(0.17)\end{array}$ & $\begin{array}{c}0.39^{* *} \\
(0.14)\end{array}$ \\
\hline Age & Yes & Yes & Yes & Yes & Yes \\
\hline Gender & Yes & Yes & Yes & Yes & Yes \\
\hline Weekly Allowance & Yes & Yes & Yes & Yes & Yes \\
\hline Church Attendance & Yes & Yes & Yes & Yes & Yes \\
\hline Family Wealth (Cars) & Yes & Yes & Yes & Yes & Yes \\
\hline Family Makeup & Yes & Yes & Yes & Yes & Yes \\
\hline Grades & Yes & Yes & Yes & Yes & Yes \\
\hline Class Size & Yes & Yes & Yes & Yes & Yes \\
\hline Observations & 436 & 436 & 436 & 435 & 435 \\
\hline Clusters & 22 & 22 & 22 & 22 & 22 \\
\hline
\end{tabular}

Notes: Robust standard errors clustered by class in parentheses. ${ }^{*}$ significant at the $10 \%$ confidence level, $* *$ significant at the $5 \%$ confidence level, $* * *$ significant at the $1 \%$ confidence level. 

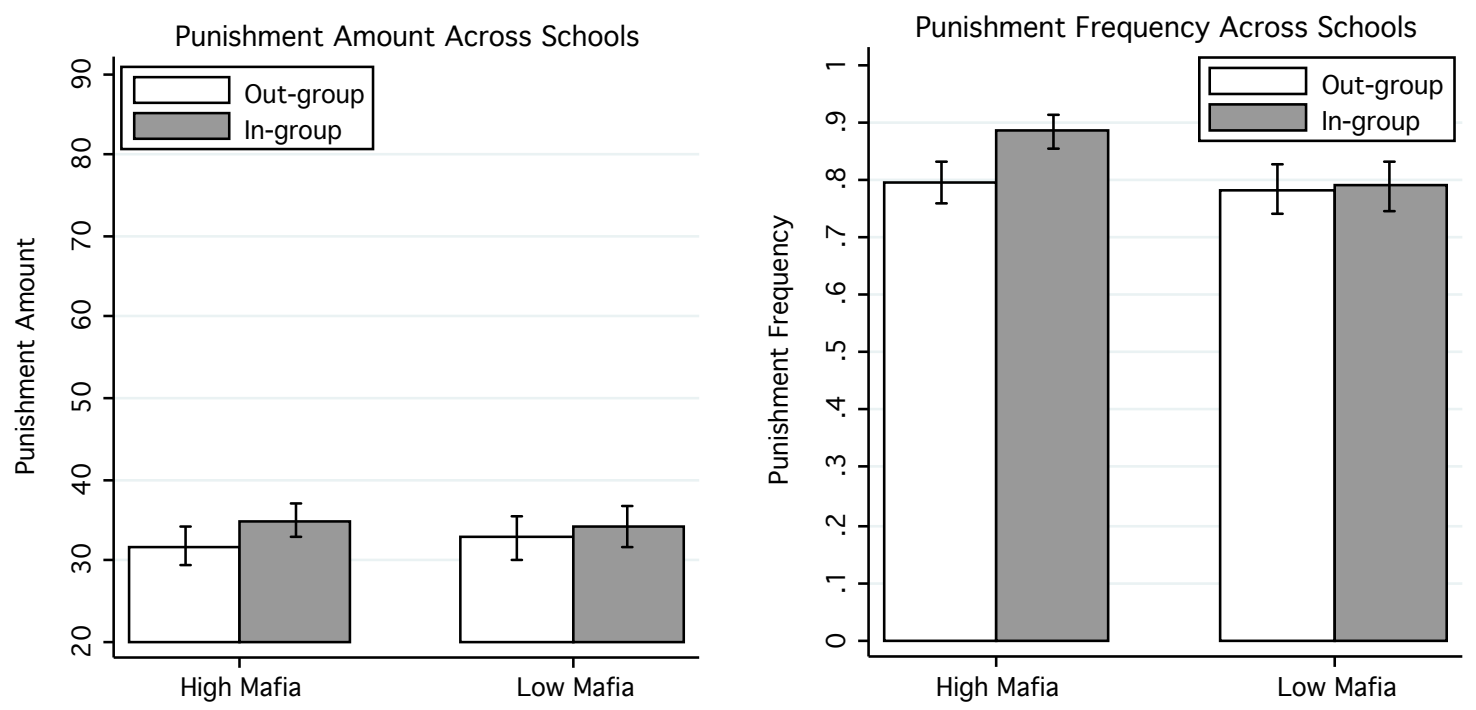

Figure 4. Punishment of Defectors. Panel A shows the average amount of punishment of individuals who didn't pass their endowment, i.e., "defectors". Panel B shows the proportion of participants who decide to punish a defector at all.

\section{Robustness}

In this section, we provide three additional robustness tests dealing with differences between the schools in the two neighborhoods.

\subsection{Age Differences}

Students in high-Mafia schools are, on average, one year older than students in the lowMafia school. Regressions with age controls (shown above), suggest that age differences across the two neighborhoods are unlikely to be driving our results. To further ensure this, we repeated our tests using the common data support from ages at the three schools, students born in 1993 and 1994, which reduces our sample to 328 students. Results on trust ( 55.2 vs. $37.8, p<.01)$ and trustworthiness are very similar (56.3 vs. $49.4, p<.1$ ), as is dictator giving (31.5 vs. 32.4, $p=.74$ ). Prisoner's dilemma results with $(73.0 \%$ vs. $65.6 \%, p=.16)$ and without (60.2\% vs. $52.4 \%, p=.18)$ punishment 
are also similar but not statistically significance at conventional levels.

\subsection{Excluding Non-Local Central Palermo Students}

As we noted earlier, 82 of the 187 students at the central Palermo school come from surrounding neighborhoods. ${ }^{17}$ Although these students are also likely impacted by the anti-Mafia culture in central Palermo, we exclude them in an additional analysis to compare students living in central Palermo with students living in Bagheria. Results for trust $(52.2$ vs. $38.9, p<.01)$, trustworthiness (56.6 vs. 48.1, $p<.05$ ), and dictator (31.0 vs. $32.7, p=.55)$ games are nearly identical to the full sample. Prisoner's dilemma results, however, are much weaker both with $(68.3 \%$ vs. $62.5 \% p=.55)$ and without (53.3\% vs. $51.1 \%, p=.68)$ punishment.

\subsection{Classroom Gender Composition}

Given the differences in gender segregation across the three schools, we next examined whether this segregation appeared to be correlated with any of our dependent variables. To do so, we exploited variation in classroom segregation at the classroom level, creating a measure of classroom segregation that is the sum of the squared proportions of male and female students. An all-male or -female classroom would therefore take on a value of one and an evenly split class a value of 0.5 . We then repeated our regressions from Table 5 for the two schools that had different mixes of gender segregation (one from Bagheria and one from Central Palermo). Including this gender segregation variable as an additional control in our regressions does not significantly change our results, but it does make the amount returned in the trust game statistical insignificance and increase precision on the parameter estimate for the prisoners dilemma with punishment game. Gender segregation is not significant in any of our specifications. Results are presented

\footnotetext{
${ }^{17}$ None of these commuting students are from Bagheria.
} 
in Appendix F.

\section{Conclusions}

Our studies suggest mistrust and in-group favoritism can be sustained by informal institutions such as organized crime long after their utility has expired. Our studies are unique in examining differences within an ethnically, religiously, and linguistically homogeneous population, overcoming some of the omitted variable biases in prior studies of cultural trust and economic activity. By keeping many cultural factors constant and exploiting a historical shock to one of them, organized crime, we are able to isolate the relationship of one informal norm with economic behavior. Furthermore, we complement the large literature on within-country variation in self-reported trust through experimental data.

These results are similar to the role of religion found by Henrich et al. (2010) in facilitating fairness and large-scale interaction, but have key differences. The informal institution in our study, organized crime, focuses pro-social behavior such as trust away from society and toward parochial interests. Furthermore, it overpowers religious and other cultural commonalities across our subjects, such as language, religion, and national identity.

Organized crime also appears to pervert the typically pro-social norm of punishment, focusing it toward in-group members in ways that only intensify in-group favoritism in cooperation. This suggests, similar to prior work (Herrmann et al., 2008; Goette et al., 2012b), that norms such as punishment that typically improve broad cooperation interact with institutions in ways that may limit their effectiveness or even produce anti-social outcomes.

Our study also shows that even in locations with well-developed formal institutions 
(i.e., Italy and the European Union), informal local institutions such as organized crime can undermine their efficacy and stifle economic exchange and growth. This suggests that the development of formal institutions is necessary but insufficient in itself, without the consideration of their interaction with informal institutions with deep historical and cultural roots. Our results are also consistent with the argument that low trust and social capital have played a critical role in impeding economic and social welfare in locations such as Sicily (Putnam et al., 1994). Our study may help explain the many difficulties faced by cross-national institutions such as the European Union. Yet our result that adolescents trusting behavior changes for the better in areas in which Mafia involvement has been successfully reduced also suggests that there is hope for overcoming the lack of trust and in-group bias exhibited in countries with informal institutions such as organized crime, historical slave trades (Nunn and Wantchekon, 2011), or caste systems (Dunning and Nilekani, 2013). Such changes can be the beginning of a path out of a vicious cycle of low trust and high organized crime.

At first glance, our results seem counter to recent work by Nese et al. (2013), who find inmates at an Italian prison who are associated with organized crime to be more cooperative than university students. We note, however, that it is difficult to compare our results with theirs, since our comparable high school samples are different on multiple dimensions from their prisoner and university samples. Recent work finds university students to be less pro-social than both the general population and even workers in highly competitive industries (e.g., see Fehr and List, 2004; Belot et al., 2010; Hoffman and Morgan, 2013). Furthermore, the in-group nature of their prisoner population is most comparable to the higher cooperation found in our in-group condition for the high-Mafia schools, so the differences in these papers must remain an open question.

Finally, we note that future work could better estimate causal treatment effects 
from localized shocks to cultures of crime by examining cohort effects in individuals of different ages. While our setup is limited in establishing causality, a longitudinal design would shed more light on how strong the causal effect of organized crime on cooperation is. Although culture and associated preferences are typically thought to change slowly over time, recent work shows this is not always the case (Alesina and Fuchs-Schundeln, 2007; Voors et al., 2012). Future research should investigate the conditions when preferences and cultural norms change slowly and when they do not. It is possible that preferences of children and teenagers (as in our study) are more malleable than those in older populations, but this would go far beyond the scope of our study and is left for future research. 


\section{References}

Abadie, Alberto and Javier Gardeazabal, "The economic costs of conflict: A case study of the Basque Country," American Economic Review, 2003, pp. 113-132.

Aghion, Philippe, Yann Algan, Pierre Cahuc, and Andrei Shleifer, "Regulation and distrust," The Quarterly Journal of Economics, 125 (3), 1015-1049.

Alesina, Alberto and Nicola Fuchs-Schundeln, "Good-Bye Lenin (or Not?): The Effect of Communism on People's Preferences," The American Economic Review, 2007, 97 (4), 1507-1528.

Algan, Yann and Pierre Cahuc, "Inherited trust and growth," The American Economic Review, 2010, pp. 2060-2092.

_ and _, "Trust, Institutions, and Development," Annual Review of Economics, 2013, 5 (1).

_, _, and Andrei Shleifer, "Teaching practices and social capital," American Economic Journal: Applied Economics, 2013, p. Forthcoming.

Ashraf, N., I. Bohnet, and N. Piankov, "Decomposing trust and trustworthiness," Experimental Economics, 2006, 9 (3), 193-208.

Baccara, M. and H. Bar-Issac, "How to Organize Crime," Review of Economic Studies, 2008, 75 (4), 1039-1067.

Bandiera, O., "Land reform, the market for protection, and the origins of the Sicilian mafia: theory and evidence," Journal of Law, Economics, and Organization, 2003, 19 (1), 218-244.

Banfield, Edward, The Moral Basis of a Backward Society, New York: New York: The Free Press, 1958.

Becker, Gary S, "Crime and punishment: An economic approach," Journal of Political Economy, 1968, 76 (2), 169-217.

Belot, Michle, Raymond Duch, and Luis Miller, "Who should be called to the lab? A comprehensive comparison of students and non-students in classic experimental games," Discussion Papers 2010001, University of Oxford, Nuffield College October 2010.

Berg, Joyce, John Dickhaut, and Kevin McCabe, "Trust, Reciprocity, and Social History," Games and Economic Behavior, 1995, 10 (1), 122-142.

Bigoni, Maria, Stefania Bortolotti, Marco Casari, Diego Gambetta, and Francesca Pancotto, "Cooperation Hidden Frontiers: The Behavioral Foundations of the Italian North-South Divide," 2013. 
Bilewicz, M. and M. Kofta, "Less Biased Under Threat? Self-Verificatory Reactions to Social Identity Threat Among Groups With Negative Self-Stereotypes," Journal of Applied Social Psychology, 2011, 41 (9), 2249-2267.

Bohnet, Iris and Steffen Huck, "Repetition and reputation: Implications for trust and trustworthiness when institutions change," The American Economic Review, 2004, 94 (2), 362-366.

_, Fiona Greig, Benedikt Herrmann, and Richard Zeckhauser, "Betrayal aversion: Evidence from Brazil, China, Oman, Switzerland, Turkey, and the United States," The American Economic Review, 2008, 98 (1), 294-310.

Bowles, Samuel, "Endogenous preferences: The cultural consequences of markets and other economic institutions," Journal of Economic Literature, 1998, 36 (1), 75-111.

_ , "Conflict: Altruism's widwife," Nature, 2008, 456, 326-327.

Brandts, Jordi and Gary Charness, "The strategy versus the direct-response method: a first survey of experimental comparisons," Experimental Economics, 2011, 14 (3), 375-398.

Buonanno, Paolo, Ruben Durante, Giovanni Prarolo, and Paolo Vanin, "Poor Institutions, Rich Mines: Resource Curse and the Origins of the Sicilian Mafia," 2012.

Cameron, A Colin and Douglas L Miller, "Robust inference with clustered data," Handbook of empirical economics and finance, 2010, pp. 1-28.

Cameron, Lisa, Nisvan Erkal, Lata Gangadharan, and Xin Meng, "Little Emperors: Behavioral Impacts of China's One-Child Policy," Science, 2013, 339 (6122), 953-957.

Charness, Gary, Luca Rigotti, and Aldo Rustichini, "Individual Behavior and Group Membership," American Economic Review, 2007, 97 (4), 1340-52.

Chen, Yan and Sherry Xin Li, "Group identity and social preferences," American Economic Review, 2009, 99 (1), 431457.

Choi, J.K. and S. Bowles, "The coevolution of parochial altruism and war," Science, 2007, 318 (5850), 636.

Dohmen, Thomas, Armin Falk, David Huffman, and Uwe Sunde, "The intergenerational transmission of risk and trust attitudes," The Review of Economic Studies, 2012, 79 (2), 645-677.

Dunning, T. and J. Nilekani, "Ethnic Quotas and Political Mobilization: Caste, Parties, and Distribution in Indian Village Councils," American Political Science Review, 2013, 107 (1). 
Falk, Armin and Christian Zehnder, "A city-wide experiment on trust discrimination," Journal of Public Economics, 2013, 100, 15-27.

Fehr, Ernst and John A. List, "The Hidden Costs and Returns of Incentives - Trust and Trustworthiness among CEOs," Journal of the European Economic Association, 2004, 2 (5), 743-71.

- and Karla Hoff, "Introduction: Tastes, Castes and Culture: the Influence of Society on Preferences," The Economic Journal, 2011, 121 (556), F396-F412.

- and Simon Gächter, "Cooperation and Punishment in Public Goods Experiments," American Economic Review, September 2000, 90 (4), 980-994.

- and Urs Fischbacher, "Third party punishment and social norms," Evolution and Human Behavior, 2004, 25, 63-87.

_, Daniela Glätzle-Rützler, and Matthias Sutter, "The development of egalitarianism, altruism, spite and parochialism in childhood and adolescence," European Economic Review, 2013, 64, 369-383.

_, Helen Bernhard, and Bettina Rockenbach, "Egalitarianism in young children," Nature, 2008, 454 (7208), 1079-1083.

Fershtman, Chaim and Uri Gneezy, "Discrimination in a Segmented Society: An Experimental Approach," Quarterly Journal of Economics, 2001, 116 (1), 351-377.

Fiorentini, Gianluca and Sam Peltzman, The economics of organised crime, Cambridge University Press, 1997.

Frey, Bruno S and Iris Bohnet, "Institutions affect fairness: Experimental investigations," Journal of Institutional and Theoretical Economics (JITE)/Zeitschrift für die gesamte Staatswissenschaft, 1995, pp. 286-303.

_, Simon Luechinger, and Alois Stutzer, "Calculating tragedy: Assessing the costs of terrorism," Journal of Economic Surveys, 2007, 21 (1), 1-24.

Friesen, J., J. Arifovic, S.C. Wright, A. Ludwig, L. Giamo, and G. Baray, "Ethnic Identity and Discrimination among Children," Journal of Economic Psychology, 2012, 33, 1156-1169.

Gambetta, D., The Sicilian mafia: The business of private protection, Cambridge: Harvard University Press, 1993.

Gneezy, A. and D.M.T. Fessler, "Conflict, sticks and carrots: war increases prosocial punishments and rewards," Proceedings of the Royal Society B: Biological Sciences, 2012, 279 (1727), 219-223. 
Goette, Lorenz, David Huffman, and Stephan Meier, "The impact of group membership on cooperation and norm enforcement: Evidence using random assignment to real social groups," The American Economic Review, 2006, 96 (2), 212-216.

_ , _ , and _ , "The Impact of Social Ties on Group Interactions: Evidence from Minimal Groups and Randomly Assigned Real Groups," American Economic Journal: Microeconomics, 2012, \& (1), 101-115.

_, _, _, and Matthias Sutter, "Competition Between Organizational Groups: Its Impact on Altruistic and Anti-Social Motivations," Management Science, 2012, 58 (5), 948-960.

Greif, Avner and Guido Tabellini, "Cultural and institutional bifurcation: China and Europe compared," The American Economic Review, 2010, 100 (2), 135-140.

- and Murat Iyigun, "Social Organizations, Violence \& Modern Growth," American Economic Review, 2013, 103 (3), 534-38.

Gueth, Werner, Hartmut Kliemt, and Stefan Napel, "Population-Dependent Costs of Detecting Trustworthiness: An Indirect Evolutionary Analysis," in Till Gruene-Yanoff and Sven Ove Hansson, eds., Preference Change, Vol. 42 of Theory and Decision Library, Springer Netherlands, 2009, pp. 243-259.

Guiso, L., P. Sapienza, and L. Zingales, "Does culture affect economic outcomes?," The Journal of Economic Perspectives, 2006, 20 (2), 23-48.

Heckman, J.J., "Skill formation and the economics of investing in disadvantaged children," Science, 2006, 312 (5782), 1900-1902.

Henrich, J., J. Ensminger, R. McElreath, A. Barr, C. Barrett, A. Bolyanatz, J.C. Cardenas, M. Gurven, E. Gwako, N. Henrich, C. Lesorogol, F. Marlowe, D. Tracer, and J. Ziker, "Markets, religion, community size, and the evolution of fairness and punishment," Science, 2010, 327 (5972), 1480-1484.

Henrich, Joseph, Robert Boyd, Samuel Bowles, Colin Camerer, Ernst Fehr, Herbert Gintis, and Richard McElreath, "In search of homo economicus: behavioral experiments in 15 small-scale societies," The American Economic Review, 2001, 91 (2), 73-78.

Herrmann, Benedikt, Christian Thoni, and Simon Gachter, "Antisocial Punishment Across Societies," Science, 2008, 319 (5868), 1362-1367.

Hoffman, Mitchell and John Morgan, "Who's Naughty? Who's Nice? Experiments on whether Pro-Social Workers are Selected Out of Cutthroat Business Environments," 2013. 
Knack, Stephen and Philip Keefer, "Does social capital have an economic payoff? A cross-country investigation," The Quarterly Journal of Economics, 1997, 112 (4), $1251-1288$.

Kollock, Peter, "The emergence of exchange structures: An experimental study of uncertainty, commitment, and trust," American Journal of Sociology, 1994, 100 (2), $313-345$.

Kumar, Vimal and Stergios Skaperdas, in Nuno Garoupa, ed., Criminal Law and Economics, Vol. 3, Edward Elgar Publishing, 2009, chapter Organized crime, pp. $257-270$.

Leeson, Peter T, "An-arrgh-chy: The Law and Economics of Pirate Organization," Journal of Political Economy, 2007, 115 (6), 1049-1094.

Levitt, Steven D and Sudhir Alladi Venkatesh, "An economic analysis of a drug-selling gang's finances," The Quarterly Journal of Economics, 2000, 115 (3), $755-789$.

Nese, Annamaria, Arturo Palomba, Patrizia Sbriglia, and Maurizio Scudiero, "Third party punishment and criminal behavior: An experiment with the Italian Camorra prison inmates," Economics Bulletin, 2013, 33, 1875-1884.

Norenzayan, A. and A.F. Shariff, "The origin and evolution of religious prosociality," Science, 2008, 322 (5898), 58-62.

North, D.C., Institutions, institutional change, and economic performance, Cambridge Univ Pr, 1990.

Nunn, Nathan and Leonard Wantchekon, "The slave trade and the origins of mistrust in Africa," American Economic Review, 2011, 101, 3221-3252.

on Drugs, United Nations Office and Crime, The globalization of crime: A transnational organized crime threat assessment, UNODC, 2010.

Pinotti, Paolo, "The economic costs of organized crime: evidence from southern Italy," Bank of Italy Temi di Discussione (Working Paper) No, 2012, 868.

Porta, Rafael La, Florencio Lopez de Silanes, Andrei Shleifer, and Robert W Vishny, "Trust in Large Organizations," The American Economic Review, 1997, pp. 333-338.

Putnam, R.D., R. Leonardi, and R. Nanetti, Making democracy work: Civic traditions in modern Italy, Princeton Univ Pr, 1994.

Santino, U., La cosa e il nome: materiali per lo studio dei fenomeni premafiosi [The thing and the name: materials for the study of pre-mafia phenomena], Vol. 66, Rubbettino, 2000. 
Sapienza, Paola, Anna Toldra-Simats, and Luigi Zingales, "Understanding trust," The Economic Journal, 2013.

Sutter, Matthias, "Individual behavior and group membership: Comment," American Economic Review, 2009, 99 (5), 2247-57.

- and Martin Kocher, "Trust and trustworthiness across different age groups," Games and Economic Behavior, 2007, 59 (2), 364-382.

Tabellini, Guido, "The scope of cooperation: Values and incentives," The Quarterly Journal of Economics, 2008, 123 (3), 905-950.

_ , "Culture and institutions: economic development in the regions of Europe," Journal of the European Economic Association, 2010, 8 (4), 677-716.

Tella, Rafael Di and Ernesto Schargrodsky, "Do police reduce crime? Estimates using the allocation of police forces after a terrorist attack," American Economic Review, 2004, pp. 115-133.

Vaccaro, Antonino, "To Pay or Not to Pay? Dynamic Transparency and the Fight Against the Mafias Extortionists," Journal of Business Ethics, 2012, 106 (1), 1-13.

Varese, F., Mafias on the move: How organized crime conquers new territories, Princeton University Press, 2011.

Voors, Maarten J, Eleonora EM Nillesen, Philip Verwimp, Erwin H Bulte, Robert Lensink, and Daan P Van Soest, "Violent conflict and behavior: a field experiment in Burundi," The American Economic Review, 2012, 102 (2), 941-964. 


\section{Appendix}

\section{A World Value Survey Questions on Trust}

In the questionnaire after the games were played, we asked participants how much they agreed with the following statements: "In general it makes sense to trust people", "Today it's impossible to trust anyone", and "When collaborating with unknown people, it's better to be prudent before trusting". Participants answer on a 7-point scale from 1 "strongly disagree" to 7 "strongly agree". In the text, we refer to the following results:

- As seen in Table A1, for two of the three statements students in the high-Mafia area exhibit less trust than students in the low-Mafia area.

Table A1: Trust Questions

\begin{tabular}{lccc}
\hline & High-Mafia & Low-Mafia & $\begin{array}{c}p \text {-value of } \\
t \text {-test }\end{array}$ \\
\hline $\begin{array}{l}\text { "In general it makes sense to trust peo- } \\
\text { ple " }\end{array}$ & $3.35(0.07)$ & $3.65(0.08)$ & 0.007 \\
"Today it's impossible to trust anyone" & $4.17(0.11)$ & $3.78(0.13)$ & 0.02 \\
"When collaborating with unknown peo- & & & \\
$\begin{array}{l}\text { ple, } \\
\text { it's better to be prudent before trusting" }\end{array}$ & $5.94(0.08)$ & $5.93(0.09)$ & 0.87 \\
\hline \# of students & 257 & 187 & \\
\hline
\end{tabular}

Notes: Means and standard errors in parenthesis. 


\section{B Trust Game Response Strategies}

In the paper we refer to the following result:

- Figure B shows a distinctly higher level of trustworthiness in the low-Mafia condition for all Player $\mathrm{X}$ transfers above $€ 0.30$ and not just for the average of the conditional amounts passed by Player Y. Our trust game used a strategy design for Player Y, such that the player decided how much to return to Player X conditional on what they received and our core analysis took the average of the conditional amounts passed by Player Y.

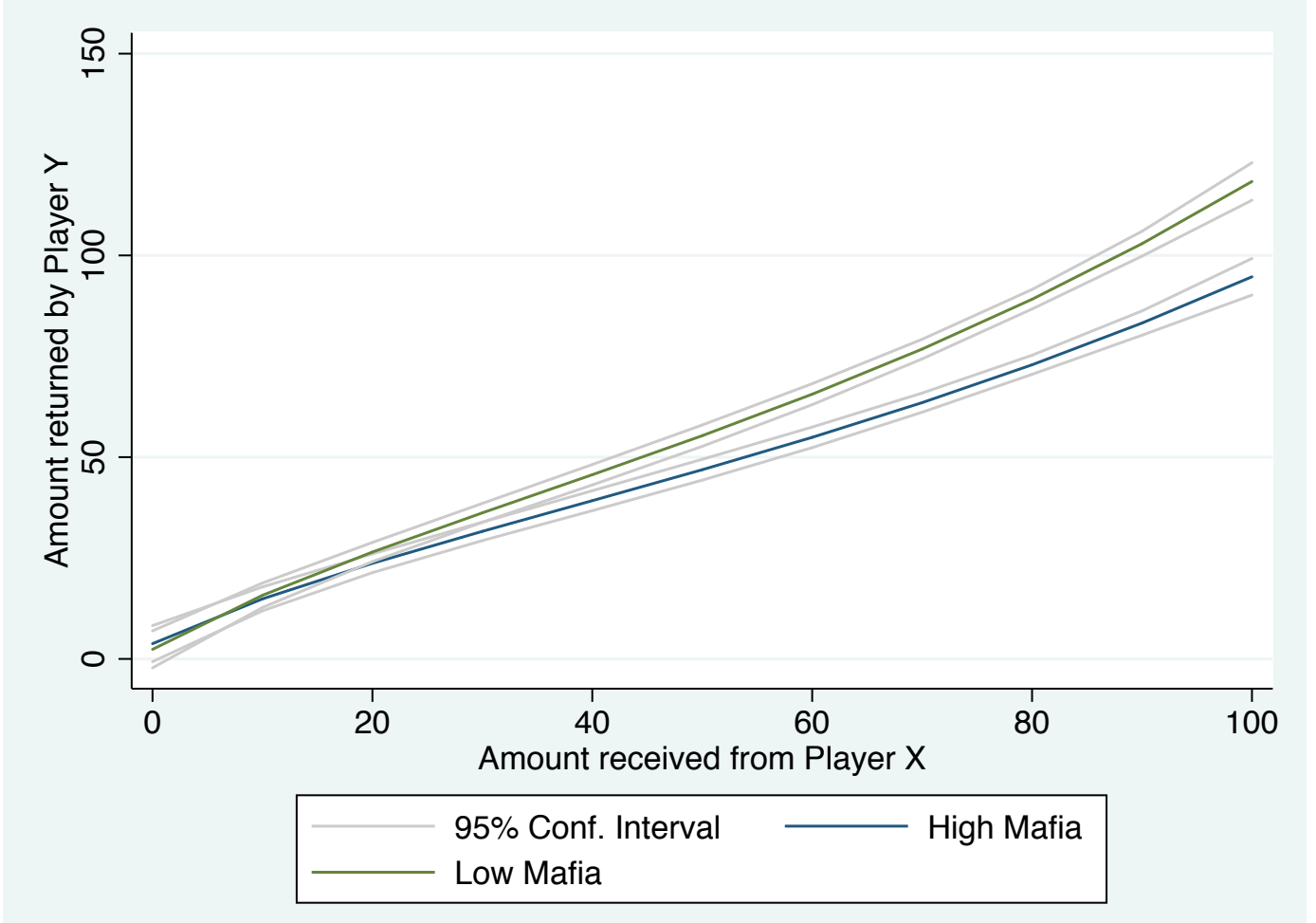

Fig. B. Transfer Strategy of Player Y in Trust Game. The figure present the average amount committed by Player $\mathrm{Y}$ in both the high- and low-Mafia conditions for each transfer amount of Player X. The lines represent the predicted relationship between Player X and Player Y transfers for both conditions, with $95 \%$ confidence intervals. 


\section{Regressions with Control Variable Coefficients}

- Table A2 shows the results of Column (5) to (9) of Table 5, but includes the coefficients and standard errors of the estimations.

Table A2: Results from Table 5 including Variable Coefficients

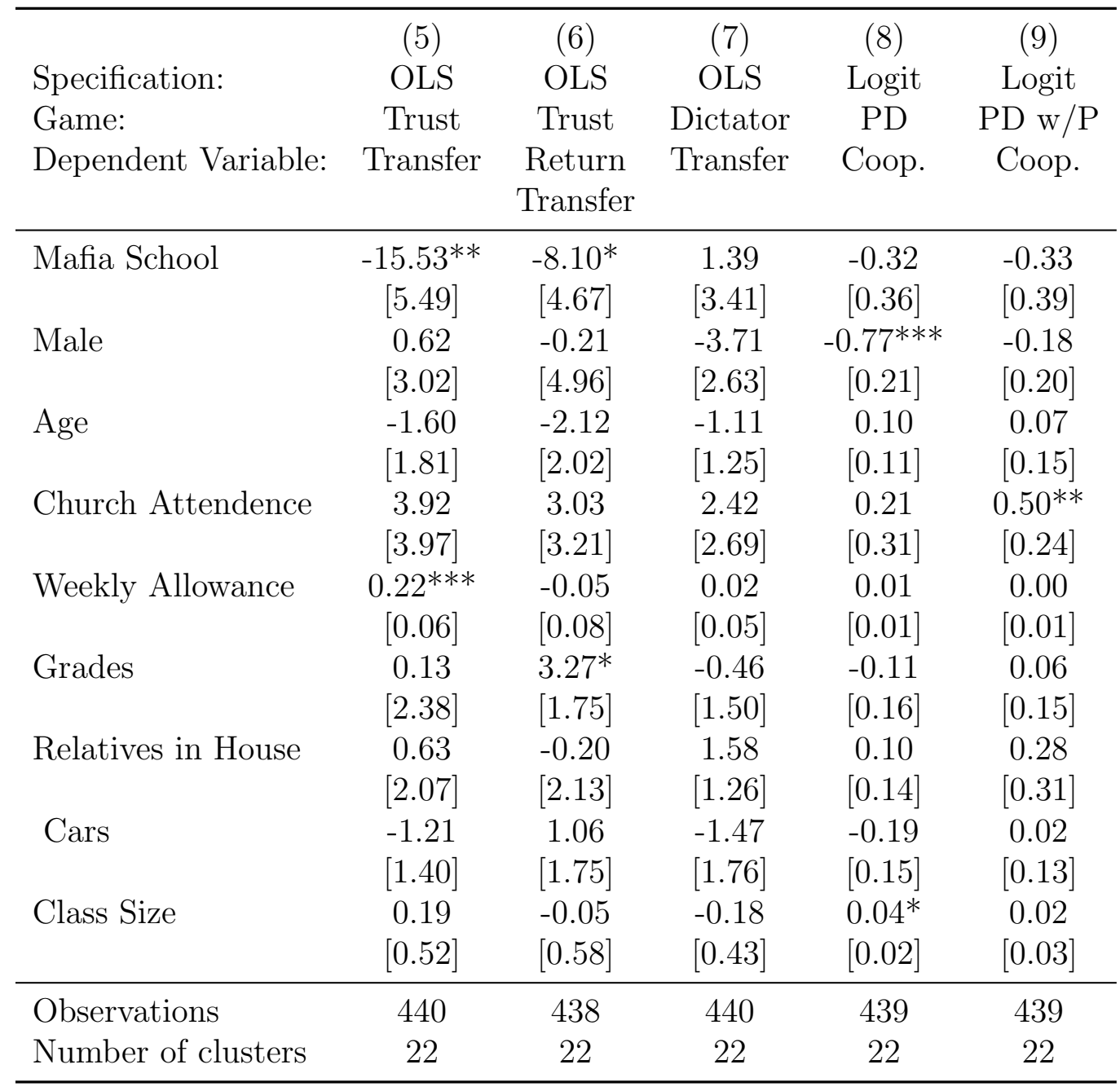

Notes: Data are pooled from both in-group and out-group conditions. Robust standard errors clustered by class in parentheses. Significance level: * $10 \%,{ }^{* *} 5 \%,{ }^{* * *} 1 \%$. 


\section{Punishment Results for All Decision Combina- tions}

- Figure D shows punishment behavior in all four cases.
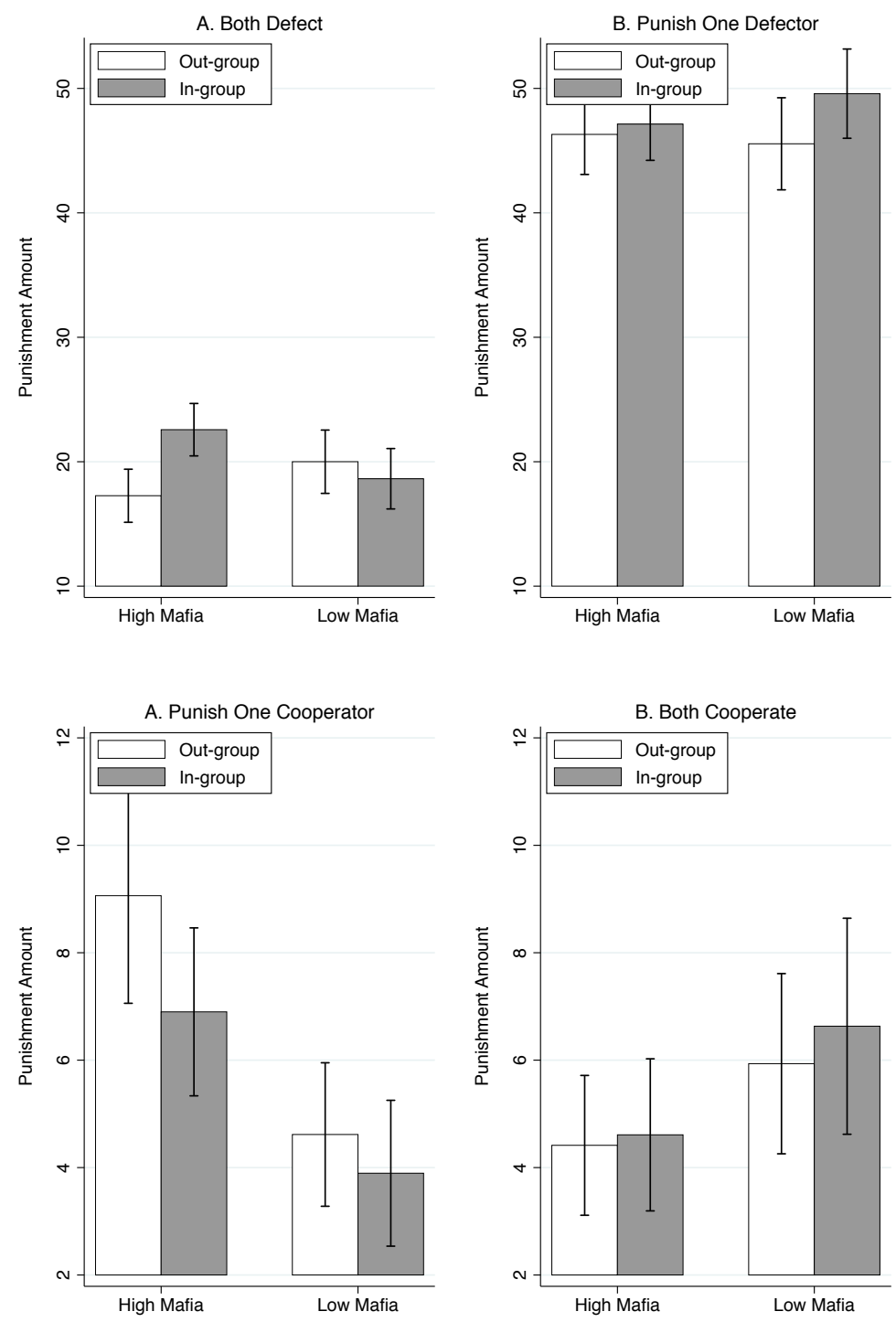

Figure Appendix D. Punishment in all four possible cases. Two figures in the top panel show average punishment amounts for the two decision combinations in prisoners' dilemma games where punished party defects. Two figures in the lower panel show average punishment amounts for the two decision combinations in prisoners' dilemma games where punished party contributes. 


\section{E Regressions Controlling for Classroom Composi- tion}

As we discussed in section 4.3, we ran regressions for each of our dependent variables controlling for classroom gender composition. We present these in the table below:

Table A3: Regressions Controlling for Classroom Gender Composition

\begin{tabular}{lccccc}
\hline & $(1)$ & $(2)$ & $(3)$ & $(4)$ & $(5)$ \\
Specification: & OLS & OLS & OLS & OLS & OLS \\
Game: & Trust & Trust & Dictator & PD & PD w/P \\
Dependent Variable: & Transfer & $\begin{array}{c}\text { Return } \\
\text { Transfer }\end{array}$ & Transfer & Coop. & Coop. \\
& & & & \\
\hline Mafia School & $-14.72^{* * *}$ & -2.41 & 1.58 & -0.22 & $-0.69^{* *}$ \\
& $(4.50)$ & $(4.82)$ & $(3.58)$ & $(0.30)$ & $(0.32)$ \\
Gender Segregation & Yes & Yes & Yes & Yes & Yes \\
Age & Yes & Yes & Yes & Yes & Yes \\
Gender & Yes & Yes & Yes & Yes & Yes \\
Weekly Allowance & Yes & Yes & Yes & Yes & Yes \\
Church Attendance & Yes & Yes & Yes & Yes & Yes \\
Family Wealth (Cars) & Yes & Yes & Yes & Yes & Yes \\
Family Makeup & Yes & Yes & Yes & Yes & Yes \\
Grades & Yes & Yes & Yes & Yes & Yes \\
Class Size & Yes & Yes & Yes & Yes & Yes \\
\hline Observations & 357 & 355 & 357 & 356 & 356 \\
\hline
\end{tabular}

Notes: Robust standard errors clustered by class in parentheses. $*$ significant at the $10 \%$ confidence level, ${ }^{* *}$ significant at the $5 \%$ confidence level, ${ }^{* * *}$ significant at the $1 \%$ confidence level. 


\section{F Questionnaire}

We would like to ask you some information.

1. What's your year of birth?

2. Sex?

- Male

- Female

3. Were you born in Italy?

- Yes

- No

4. Where did you live most of your life? (Italy, Out of Italy)

5. In which area (neighborhood) of the city do you live?

6. What's your religion?

- Catholic (active)

- Catholic (non active)

- Other (provide some info, please)

7. How often do you attend religious celebrations?

- Daily

- Weekly

- Monthly

- only for religious holidays

- Rarely/never

8. How many of your classmates are your friends?

9. How many of your schoolmates are your friends?

10. The average of my grades is:

- 4

- 5

- 6

- 7 
11. What profession you would like to pursue when you will be an adult? Some questions about your family:

12. What's your father's profession?

13. And that of your mother?

14. How many older brothers / sisters do you have?

15. How many younger brothers and sisters do you have?

16. Besides your parents and your brothers/sisters, how many other relatives (aunts/uncles/grandparents ect.) live with you?

17. Excluding your parents, your brothers and sisters, how many relatives (grandfather, uncle, etc.) live in your apartment?

18. How many cars does your family own? (please consider everyone living in your apartment)?

19. Your last trip (vacation): where did you go and for how many days?

20. Do you receive some money every week from your parents? If yes, how much? Some questions about various issues

21. Please, indicate if you agree or disagree with each of these statements. Please use the scale from 1 "strongly disagree" to 7 "strongly agree":

(a) "In general it makes sense to trust people"

(b) "Today it's impossible to trust anyone"

(c) "When collaborating with unknown people, it's better to be prudent before trusting"

(d) "Mafia is on the wrong side"

(e) "Mafia substitutes for the State because it provides work and security to people"

(f) "In general, the impact of the Mafia on the Sicilian society is positive"

22. In general, what's the Mafia's impact on your friends and your family?

- Mafia, in the end, has a positive impact

- Mafia does not have an impact

- Mafia has a negative impact 
23. Please, indicate the impact of Mafia on the environment where you live:

- A lot

- A little

- Moderate

24. Please, indicate what other people think about Mafia's impact on the Sicilian society (consider an average value):

- Mafia, in the end, has a positive impact

- Mafia does not have an impact

- Mafia has a negative impact

25. Please, indicate, according to other people's opinion, the impact of Mafia on the environment where you live: (consider an average value)

- A lot

- A little

- Moderate

26. How would you evaluate your classmates' willingness to help you?

- Willing

- Relatively willing

- Neutral

- Relatively selfish

- Selfish

27. How would you evaluate your schoolmates' willingness to help you (excluding your classmates)?

- Willing

- Relatively willing

- Neutral

- Relatively selfish

- Selfish

28. On a scale from 1 "not attractive at all" to 7 "very attractive", how attractive do you think you are to your classmates?

29. Think about the environment where you live (school, family, friends, etc.). Please, evaluate the percentage of those that: 
(a) Have an antiMafia position: \%

(b) Are indifferent to Mafia: \%

(c) Although tacitly, are pro Mafia: \%

Note: $a+b+c=$ should be $100 \%$

\section{Thanks!}


G In-Group Condition Instructions (translated from Italian) 


\section{Welcome to this game!}

Here's how you play this game.

Please note that the procedure does NOT allow us to trace the identity of those who complete the questionnaire. The secret identification code is needed only to match the questionnaire and the results of the various games. Please do NOT give your PIN to anyone, not even the professors or persons responsible for this program.

\section{DECISION}

Person $\mathrm{X}$ and person $\mathrm{Y}$ will have to make a decision at the same time :

\section{Person X}

- Person X will have 1 euro. Person Y as well (1 euro )

- Person X makes the first move : he must decide how much he wants to give person $\mathrm{Y}$ of his/her euro. $\mathrm{He} / \mathrm{she}$ can give any value between 0 and 1 euro, at intervals of 10 cents (so $0 \mathrm{c}, 10 \mathrm{c}, 20 \mathrm{c}$, $30 \mathrm{c}, \ldots, 90 \mathrm{c}, € 1)$

- The amount that $\mathrm{X}$ has decided to give person $\mathrm{Y}$ will be multiplied by three.

So if Person $\mathrm{X}$ decides to give you 10 cents, you (you are person $\mathrm{Y}$ ) will receive 30 cents

\section{Person $Y$}

- Person $\mathrm{Y}$ receives three times what $\mathrm{X}$ has sent (in addition to the euro which he/she had already at the beginning of the game)

- Person $\mathrm{Y}$ at this point has to decide how much money he/she wants to give back to X: she give, only in intervals of 10 cents, for any value between 0 cents and what he has available ( 1 euro more than he received, multiplied by 3 , from $\mathrm{X}$ )

- Note: the money given back to $\mathrm{X}$ from $\mathrm{Y}$ will not be tripled. So if $\mathrm{Y}$ decides to give back 20 cents $\mathrm{X}$ will receive exactly 20 cents

\section{Example:}

Person $\mathrm{X}$ decides to give 20 cents to the person $\mathrm{Y}$

Person $\mathrm{X}$ is left with 80 cents

Person $Y$ is left with $€ 1$ (initial) $+20 c * 3=1$ euro and 60 cents

$\mathrm{Y}$ may decide to give back what she wants. If, for example, $\mathrm{Y}$ decides to give 10 cents to $\mathrm{Y}$

In the end, person $X$ will have 80 cents +10 cents $=90$ cents

Person $\mathrm{Y}$ end up with $1.60-10=€ 1.50$ 


\section{TEST}

To see if you understand the logic of the game:

Please note this is only a test!

The real game will be on the next page!

Example 1: You are person $X$, at the beginning you have 1 euro and you decide to give 30 cents;

Y decides to give you 10 cents

How much money do you have?

How much money remains with Y?

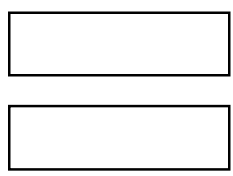

Example 2: You are person $X$, at the beginning you have 1 euro and you decide to give 50 cents

\section{$Y$ decides to give you 50 cents}

How much money do you have?

How much money remains with Y?
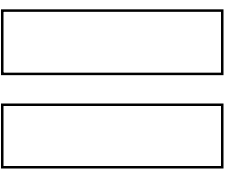

Example 3: You are person $\mathrm{X}$ and decide to give 1 euro to person $\mathrm{Y}$

$\mathrm{Y}$ decides to give you 0 cents

How much money do you have?

How much money remains with Y?

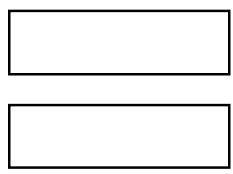


This is the real game!

Remember, you are person $\mathrm{X}$

How much money would you like to give to Y?

\begin{tabular}{|c|c|c|c|c|}
\hline \multicolumn{2}{|c|}{ I give } & & I keep & $\begin{array}{l}\text { Y receives } \\
\text { (This value will be added to the } \\
\text { initial amount) }\end{array}$ \\
\hline$\square$ & $0 \mathrm{c}$ & $\rightarrow$ & $1 €$ & 0 \\
\hline$\square$ & $10 \mathrm{c}$ & $\rightarrow$ & $90 \mathrm{c}$ & $30 c$ \\
\hline$\square$ & $20 \mathrm{c}$ & $\rightarrow$ & $80 \mathrm{c}$ & $60 c$ \\
\hline$\square$ & $30 \mathrm{c}$ & $\rightarrow$ & $70 \mathrm{c}$ & $90 \mathrm{c}$ \\
\hline$\square$ & $40 c$ & $\rightarrow$ & $60 c$ & $1 €$ e $20 \mathrm{c}$ \\
\hline$\square$ & $50 \mathrm{c}$ & $\rightarrow$ & $50 \mathrm{c}$ & $1 €$ e $50 \mathrm{c}$ \\
\hline$\square$ & $60 \mathrm{c}$ & $\rightarrow$ & $40 \mathrm{c}$ & $1 €$ e $80 \mathrm{c}$ \\
\hline$\square$ & $70 \mathrm{c}$ & $\rightarrow$ & $30 c$ & $2 €$ e $10 \mathrm{c}$ \\
\hline$\square$ & $80 \mathrm{c}$ & $\rightarrow$ & $20 c$ & $2 € 40 \mathrm{c}$ \\
\hline$\square$ & $90 \mathrm{c}$ & $\rightarrow$ & $10 \mathrm{c}$ & $2 € 70 \mathrm{c}$ \\
\hline$\square$ & $1 €$ & $\rightarrow$ & $0 €$ & $3 €$ \\
\hline
\end{tabular}

REMEMBER THAT IN TERMS OF YOUR OFFER, Y DECIDES THE AMOUNT OF MONEY THAT WILL EVENTUALLY COME TO YOU, AS IN THE PREVIEW GAMES

REMEMBER THAT Y will decided the amount to sent you back in relation to your previous transfer 


\section{Welcome to this new game !}

In this game, you will be assigned at random to a partner from your class. Neither you nor your partner will ever know the identity of the other. You 'll play the part of person Y while your anonymous partner will be person $\mathrm{X}$.

\section{DECISION}

Person $\mathrm{X}$ and person $\mathrm{Y}$ will have to make a decision at the same time :

\section{Person $X$}

- Person X will have 1 euro. Person Y as well (1 euro )

- Person X makes the first move : he/she must decide how much he/she wants to give person Y of his euro. He/she can give any value between 0 and 1 euro, at intervals of 10 cents (so $0 \mathrm{c}, 10 \mathrm{c}$, 20c, 30c, ..., 90c, €1)

- The amount that $\mathrm{X}$ has decided to give person $\mathrm{Y}$ will be multiplied by three.

So if Person $\mathrm{X}$ decides to give you 10 cents, you (you are person $\mathrm{Y}$ ) will receive 30 cents

\section{Person $Y$}

- Person Y receives three times what $\mathrm{X}$ has sent (in addition to the euro which he had already at the beginning of the game)

- Person Y at this point has to decide how much money he/she wants to give back to X: she give, only in intervals of 10 cents, for any value between 0 cents and what he has available ( 1 euro more than he received, multiplied by 3 , from $\mathrm{X}$ )

- Note: the money given back to X from Y will not be tripled. So if Y decides to give back 20 cents $\mathrm{X}$ will receive exactly 20 cents

\section{Example:}

Person $\mathrm{X}$ decides to give 20 cents to the person $\mathrm{Y}$

Person $\mathrm{X}$ is left with 80 cents

Person $Y$ is left with $€ 1$ (initial) $+20 \mathrm{c} * 3=1$ euro and 60 cents

$\mathrm{Y}$ may decide to give back what she wants. If, for example, $\mathrm{Y}$ decides to give 10 cents to $\mathrm{Y}$

In the end, person $X$ will have 80 cents +10 cents $=90$ cents

Person Y end up with $1.60-10=€ 1.50$ 
Test to see if you understand the logic of the game:

Please note this is only a test!

The real game will be on the next page!

Example 1: Person $X$, at the beginning decides to give 1 euro and 20 cents

You, $Y$, choose to give 10 cents

How much will person $\mathrm{X}$ end up with?

How much will remain for you, Y?

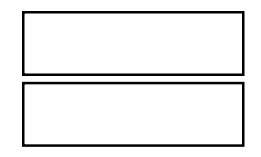

Example 2: Person $X$, at the beginning, decides to give 50 cents

You, $Y$, choose to give 50 cents

How much will person $\mathrm{X}$ end up with?

How much will remain for you, Y?
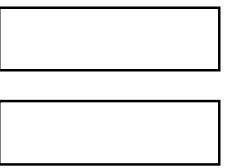

Example 3: Person $\mathrm{X}$ decides to give 1 euro

You, $Y$, decide to give 0 cents

How much will person X end up with?

How much will remain for you, Y?

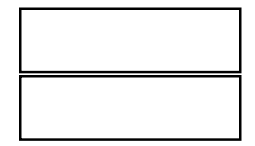


This is the real game!

\section{You are person $\mathbf{Y}$}

\begin{tabular}{|c|c|c|c|c|c|c|}
\hline $\begin{array}{l}\text { If the } \\
\text { person } \mathrm{X} \\
\text { gives you: }\end{array}$ & & Person X keeps & $\begin{array}{l}\text { Therefore, I will } \\
\text { have at my } \\
\text { disposal: }\end{array}$ & & $\begin{array}{l}\text { I want to keep } \\
\text { in total: }\end{array}$ & $\begin{array}{l}\text { Therefore I will } \\
\text { send to person X } \\
\text { the following: }\end{array}$ \\
\hline $0 \mathrm{c}$ & $\rightarrow$ & $1 €$ & $1 €$ & $\rightarrow$ & & \\
\hline $10 \mathrm{c}$ & $\rightarrow$ & $90 \mathrm{c}$ & $1 €$ e $30 \mathrm{c}$ & $\rightarrow$ & & \\
\hline $20 \mathrm{c}$ & $\rightarrow$ & $80 \mathrm{c}$ & $1 €$ e $60 \mathrm{c}$ & $\rightarrow$ & & \\
\hline $30 \mathrm{c}$ & $\rightarrow$ & $70 \mathrm{c}$ & $1 €$ e $90 \mathrm{c}$ & $\rightarrow$ & & \\
\hline $40 \mathrm{c}$ & $\rightarrow$ & $60 \mathrm{c}$ & $2 €$ e $20 c$ & $\rightarrow$ & & \\
\hline $50 \mathrm{c}$ & $\rightarrow$ & $50 \mathrm{c}$ & $2 €$ e $50 \mathrm{c}$ & $\rightarrow$ & & \\
\hline $60 \mathrm{c}$ & $\rightarrow$ & $40 \mathrm{c}$ & $2 €$ e $80 c$ & $\rightarrow$ & & \\
\hline $70 \mathrm{c}$ & $\rightarrow$ & $30 \mathrm{c}$ & $3 €$ e $10 \mathrm{c}$ & $\rightarrow$ & & \\
\hline $80 \mathrm{c}$ & $\rightarrow$ & $20 \mathrm{c}$ & $3 €$ e $40 c$ & $\rightarrow$ & & \\
\hline $90 \mathrm{c}$ & $\rightarrow$ & $10 \mathrm{c}$ & $3 €$ e $70 c$ & $\rightarrow$ & & \\
\hline $1 €$ & $\rightarrow$ & $1 €$ & $4 €$ & $\rightarrow$ & & \\
\hline
\end{tabular}




\section{Welcome to this new game!}

In this game, you will be assigned at random a partner from this class. Neither you nor your partner will ever know the identity of the other. You'll play the part of person A1 while your anonymous partner will be person A2.

DO NOT FORGET: YOU ARE PLAYER A1

\section{DECISION}

Persons A1 and A2 will have to make a decision at the same time:

At the beginning of the game, both $\mathrm{A} 1$ and $\mathrm{A} 2$ have access to 1 euro

Both A1 and A2 can choose between two solutions:

I. Hold: keep your Euro with you.

II. Pass: i.e. give money to your Unknown counterpart. When you spend the money, your euro is multiplied by 2 , so your Unknown counterpart receives 2 euro

So both you and your partner / counterpart can choose to retain or send the money. There are therefore 4 possible scenarios of the game:

You hold $1 €$

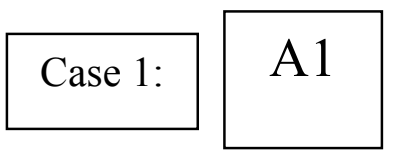

You pass $1 €$

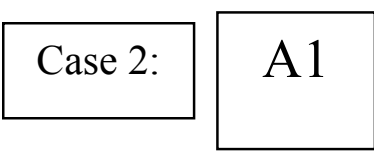

You hold $1 €$
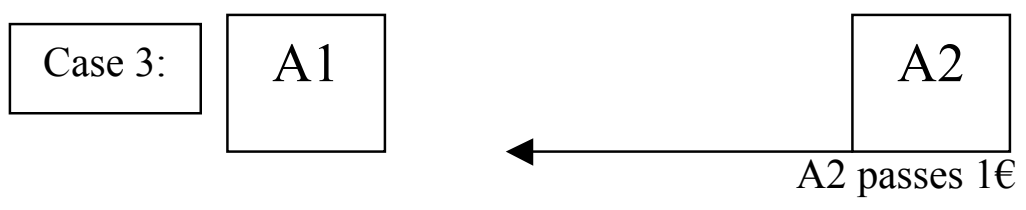

You pass $1 €$

Case 4:

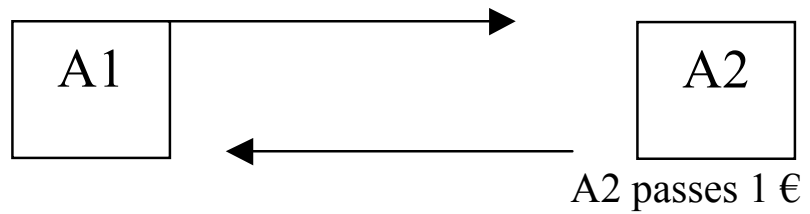

A2 holds $1 €$
At the end:

A1 (you) will have: 1 euro A2: will have: 1 euro

At the end:

A1(you) will have: 0 euro A2 will have: 3 euro

At the end:

A1(you) will have: 3 euro A2 will have: 0 euro

Alla fine:

A1(you) will have: 2 euro A2 will have: 2 euro 


\section{TEST}

To see if you understand the logic of the game:

Please note this is only a test!

The real game will be on the next page!

Example 1: You (A1) pass $1 €$, while person A2 holds $1 €$

At the end of the game, how much money does each player have?

A1 (You):

A2:

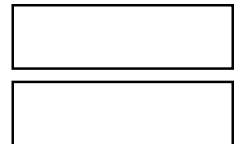

Example 2: You (A1) hold $1 €$ while person la $A 2$ passes you $1 €$

At the end of the game, how much money does each player have?:

A1 (You):

A2:

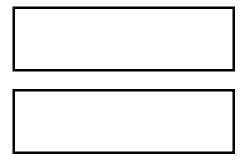

Example 3: You hold $1 €$ and person A2 holds $1 €$

At the end of the game, how much money does each player have?

A1 (You)

A2

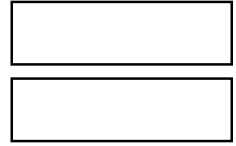


- Remember, you are player A1:

- Player A2 will be your anonymous classmate

Hold or pass your euro?

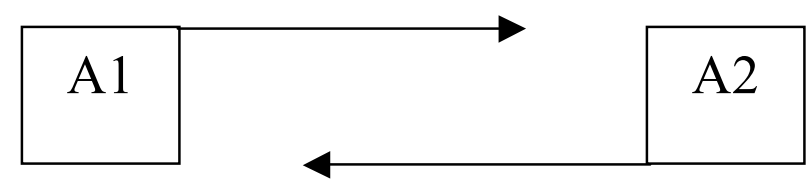

(Hold or passes his/her euro?)

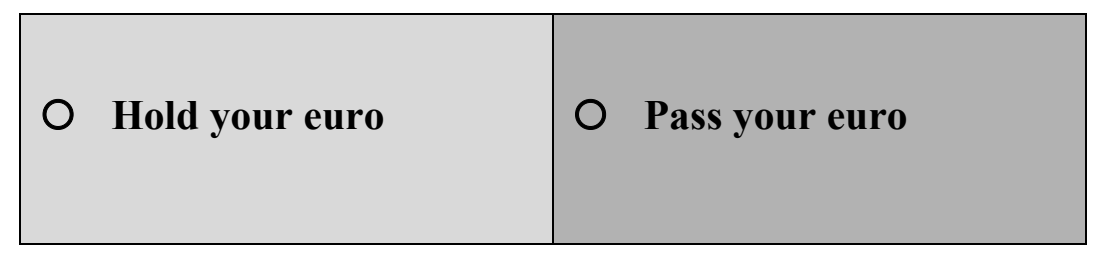




\section{Welcome to this new game!}

This game is a modified version of the previous one. Only this time, you will also need to decide on a punishment.

The game is divided into two parts.

In the first part, you will need to decide on a penalty to be applied to a classmate who is playing this game with another person.

CONSIDER THE 4 SITUATIONS THAT WE SAW BEFORE:

A1 holds $1 €$

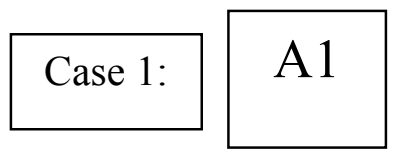

A2

A2 holds $1 €$

A1 passes $1 €$

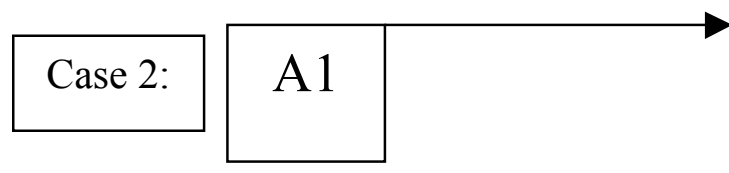

A2

A2 holds $1 €$

A1 holds $1 €$
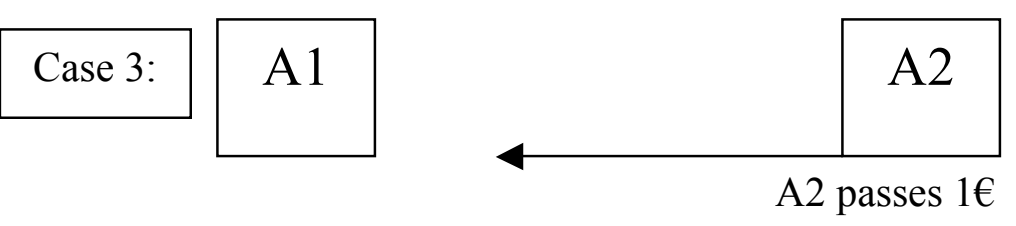

A1 passes $1 €$

Case 4:

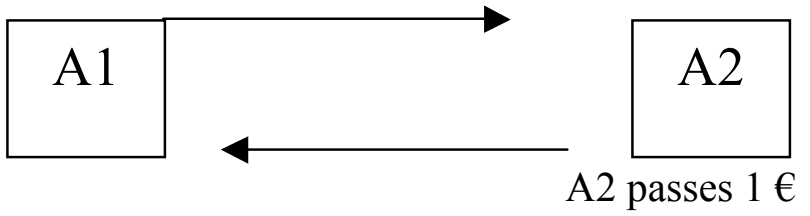

At the end:

A1 will have: 1 euro

A2 will have: 1 euro

At the end:

A1 will have: 0 euro

A2 will have: 3 euro

At the end:

A1 will have: 3 euro

A2 will have: 0 euro

At the end:

A1 will have: 2 euro

A2 will have: 2 euro 


\section{THE PUNISHMENT}

Now, imagine that you are an arbitrator who is not part of the transaction between A1 and A2 and must decide a punishment for A1. What punishment do you want to apply to A1 in each of the situations described above?

Consider that for this stage of the game you'll have 90 cents for punishment.

You can choose to use any value between 0 and 90 cents for punishment (always in increments of 10 cents). What you do not spend on your punishment will be added to your prize from all the games.

Consider that when you punish your partner, you lose the money you have decided to use for punishment, but the value you use for the punishment is tripled to punish your partner.

So if you decide to use 50 cents for punishment, A1 will lose 150 cents. ( 1 euro and 50 cents) while you remain 40 cents.

If you decide to use 90 cents, A1 will lose 2 Euros and 70 cents while you will remain with 0. 


\section{HOW MUCH WOULD YOU LIKE TO PUNISH A1 IF ... ?}

A1 holds $1 €$

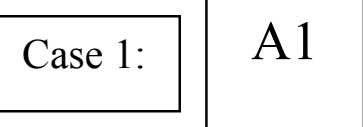

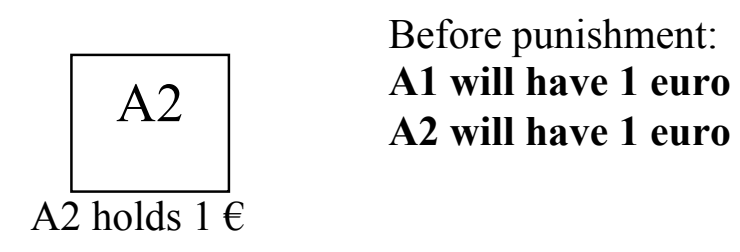

How much money (of your 90 cents) would you like to use to punish A1 in case 1 ?

A1 passes $1 €$
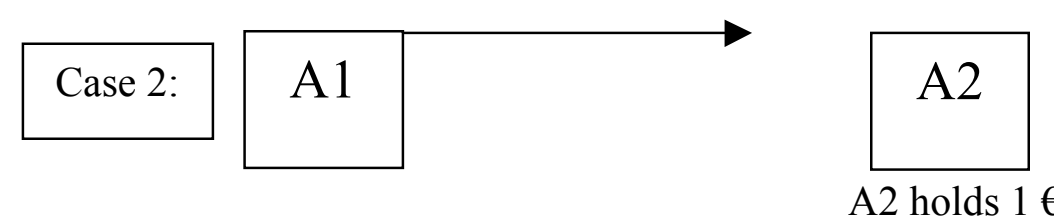

Before punishment:

A1 will have: 0 euro

A2 will have: 3 euro

A2 holds $1 €$

How much money (of your 90 cents) would you like to use to punish A1 in case 2?

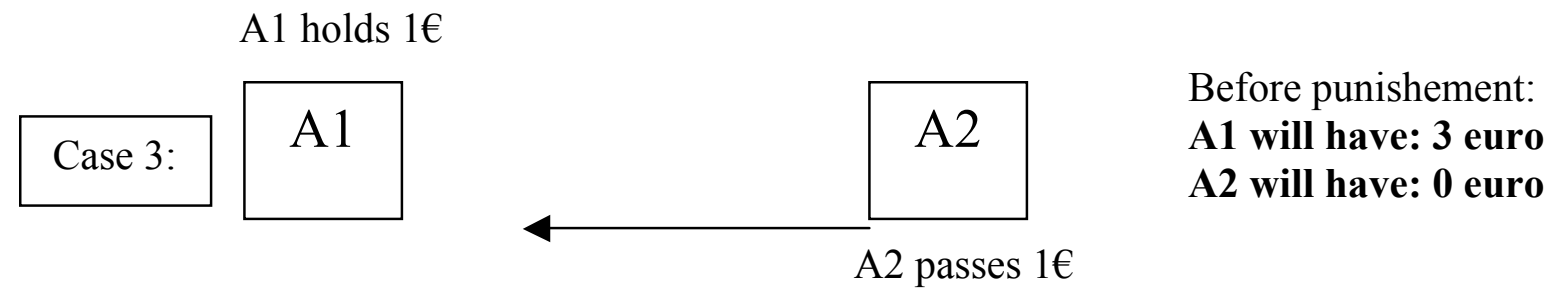

How much money (of your 90 cents) would you like to use to punish A1 in case 3 ?

A1 passes $1 €$

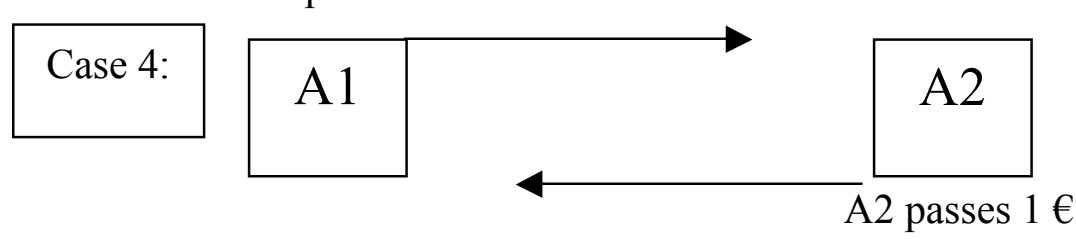

Before punishment:

A1 will have: 2 euro

A2 will have: 2 euro

How much money (of your 90 cents) would you like to use to punish A1 in case 4 ? 
Ok, now that you've decided the punishment that you intend to apply as an arbitrator, you can complete the transaction as in the previous game. Remember that you have 1 euro, and the exchange mechanisms are those explained on page 1.

- Remember, you are the player A1:

- Player A2 will be your anonymous partner

- This time, however, after the transaction, the money you have earned will have subtracted from it the punishment decided by a third anonymous arbitrator.

Hold or pass your euro?
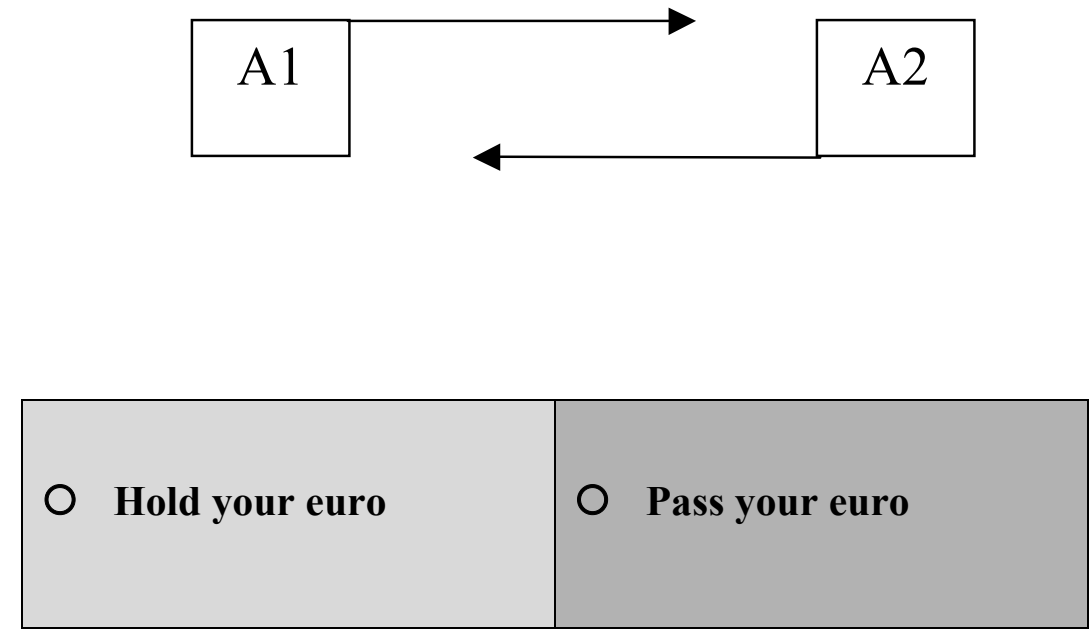


\section{Welcome to this new game!}

\section{YOUR DECISION}

You have been assigned the role of the decision maker, that is, you will receive an amount and choose how to distribute it to a classmate whose identity you will never know and who will never know your identity.

- You will be assigned 1 euro

- You have complete freedom to give the amount you want to your partner.

- You can give (in cents) any value between 0 and 1 euro in intervals of ten cents : $0,10,20,30,40,50,60,70,80,90,1 €$,

- Your anonymous colleague (imagine that his name is Alfonso), will receive exactly what you have decided to offer him. You will receive the remainder. For example, if you've decided to give 10 cents to your colleague (Alfonso), you will receive 90 cents while Alfonso receives exactly 10 cents.

- Consider that in addition to the money you earn as described above, you will receive a sum which will be decided by another classmate (e.g., Mario), which is not the one who received your offer .

All clear? 


\section{TEST}

To see if you understand the logic of the game:

Please note this is only a test!

The real game will be on the next page!

Example 1: You decide to give 20 cents to your partner

I keep:

My partner receives:

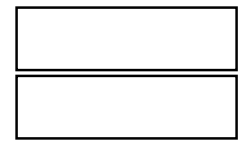

Example 2: You decide to give 50 cents to your partner

I keep:

My partner receives:

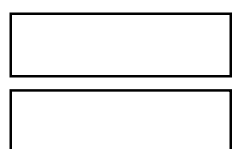

Example 3: $\quad$ You decide to give 30 cents to your partner

I keep:

My partner receives:

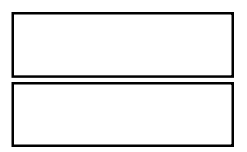




\section{This is the real game:}

So, how much money did you choose to give your partner?

Please mark with a cross the amount you wish to give to them:
I decide to give:
I keep:
My partner receives

\begin{tabular}{|c|c|c|c|c|}
\hline$\square$ & $0 \mathrm{c}$ & $\rightarrow$ & $1 €$ & 0 \\
\hline$\square$ & $10 \mathrm{c}$ & $\rightarrow$ & 90 cent & 10 \\
\hline$\square$ & $20 c$ & $\rightarrow$ & 80 cent & 20 \\
\hline$\square$ & $30 c$ & $\rightarrow$ & 70 cent & 30 \\
\hline$\square$ & $40 c$ & $\rightarrow$ & 60 cent & 40 \\
\hline$\square$ & $50 c$ & $\rightarrow$ & 50 cent & 50 \\
\hline$\square$ & $60 c$ & $\rightarrow$ & 40 cent & 60 \\
\hline$\square$ & $70 c$ & $\rightarrow$ & 30 cent & 70 \\
\hline$\square$ & $80 c$ & $\rightarrow$ & 20 cent & 80 \\
\hline$\square$ & $90 c$ & $\rightarrow$ & 10 cent & 90 \\
\hline$\square$ & $1 €$ & $\rightarrow$ & $0 €$ & $1 €$ \\
\hline
\end{tabular}

